Published in final edited form as:

Nat Rev Drug Discov. ; 10(11): 835-852. doi:10.1038/nrd3578.

\title{
Perspectives and opportunities for nanomedicine in the management of atherosclerosis
}

\author{
Mark E. Lobatto ${ }^{\star}, \ddagger$, Valentin Fuster§,\|, Zahi A. Fayad ${ }^{\star}$, and Willem J. M. Mulder ${ }^{\star}, \ddagger$ \\ *Translational and Molecular Imaging Institute, Mount Sinai School of Medicine, One Gustave L. \\ Levy Place, BOX 1234, New York 10029, USA. ¥Department of Vascular Medicine, Academic \\ Medical Center, Meibergdreef 9, 1105 AZ, Amsterdam, The Netherlands. §Department of \\ Cardiology, Zena and Michael A. Weiner Cardiovascular Institute and Marie-Josée and Henry R. \\ Kravis Cardiovascular Health Center, Mount Sinai School of Medicine, One Gustave L. Levy \\ Place, New York 10029, USA. "Centro Nacional de Investigaciones Cardiovasculares (CNIC), 3 \\ Melchor Fernández Almagro Street, 28029 Madrid, Spain.
}

\begin{abstract}
The use of nanotechnology for medical purposes — nanomedicine - has grown exponentially over the past few decades. This is exemplified by the US Food and Drug Administration's approval of several nanotherapies for various conditions, as well as the funding of nanomedical programmes worldwide. Although originally the domain of anticancer therapy, recent advances have illustrated the considerable potential of nanomedicine in the diagnosis and treatment of atherosclerosis. This Review elaborates on nanoparticle-targeting concepts in atherosclerotic disease, provides an overview of the use of nanomedicine in atherosclerosis, and discusses potential future applications and clinical benefits.
\end{abstract}

\begin{abstract}
Nanomedicine has been defined as "applications of nanotechnology for treatment, diagnosis, monitoring, and control of biological systems"1. These applications range from targeted therapy, in vivo imaging and in vitro diagnostics to biomaterials and active implants ${ }^{2}$. Nanoparticles, which are typically in the range of $1-100 \mathrm{~nm}$ in size, are similar in scale to biological macromolecules such as proteins and $\mathrm{DNA}^{3}$. Importantly, intrinsic physical properties of materials at this level may change, providing fundamentally different properties from the bulk material ${ }^{4}$. Nanoparticles can be composed of organic materials such as lipids, metallic or inorganic materials such as iron oxide and gold, or combinations of these materials ${ }^{5}$. Nanoparticle fabrication can be precisely controlled, which allows their size to be varied and their shape, surface charge, stability and various other characteristics to be modified to ultimately influence particle behaviour in vivo ${ }^{6}$. Moreover, nanoparticles exhibit a high surface to volume ratio, allowing the surface coating to be exploited for derivatization with a variety of molecules. This is of exceptional interest for surface interactions but also facilitates multifunctionality and functionalization for specific
\end{abstract}

\footnotetext{
(C) 2011 Macmillan Publishers Limited. All rights reserved

Correspondence to W.J.M.M. willem.mulder@mountsinai.org.

Competing interests statement

The authors declare no competing financial interests.

FURTHER INFORMATION

Author's homepage: http://www.mssm.edu/profiles/willem-jm-mulder

Translational and Molecular Imaging Institute website: http://www.tmii.org/nanomedicine_landingpage.html

ClinicalTrials.gov: http://clinicaltrials.gov

ALL LINKS ARE ACTIVE IN THE ONLINE PDF
} 
applications. Among the different nanomedical applications, nanoparticle-based drug delivery has been most extensively explored. Its advantages include — but are not limited to - improving drug pharmacokinetics and enabling the therapeutic use of drugs that exhibit certain drawbacks, such as low water-solubility, poor bioavailability, fast metabolism, limited specificity or severe adverse effects ${ }^{7,8}$.

One of the first clinically approved nanomedicinal therapies was a liposomal formulation of doxorubicin, a cytotoxic drug used for cancer chemotherapy. This formulation, branded Doxil, was approved by the US Food and Drug Administration in 1995 for the treatment of Kaposi's sarcoma and later approved for other cancer types. Subsequently, several other nanomedicinal therapeutics have been approved as anticancer treatments, including liposomal daunorubicin (DaunoXome; Gilead Sciences), applied in patients with advanced HIV-related Kaposi's sarcoma, and an albumin-bound nanoparticle delivering paclitaxel for the treatment of breast cancer (Abraxane; Abraxis BioScience) after failure of initial treatment for metastatic disease or relapse ${ }^{9}$. Encapsulation of doxorubicin, for example, in liposomes results in favourable pharmacokinetics compared to the free drug by significantly reducing clearance of the drug from the bloodstream, and the main side effect cardiotoxicity - is substantially reduced ${ }^{10,11}$.

Besides their therapeutic use, nanoparticles can be incorporated or labelled with small molecules, chelated ions, metals or nanocrystals to enable their detection by diagnostic imaging. For example, nanoparticles can be incorporated or labelled with: the gadolinium ion $\left(\mathrm{Gd}^{3+}\right)$ or iron oxide nanocrystals for magnetic resonance imaging (MRI) ${ }^{12}$; electrondense materials such as gold and bismuth for X-ray and computed tomography (CT) imaging ${ }^{13}$; radiolabels such as ${ }^{18} \mathrm{For}{ }^{64} \mathrm{Cu}$ for positron emission tomography (PET) and ${ }^{111}$ In for single-photon emission computed tomography (SPECT) imaging ${ }^{14}$; and fluorophores or quantum dots for optical imaging ${ }^{15}$.

Although its primary application was initially in cancer, nanomedicine has seen tremendous growth and extension beyond oncological applications in the twentieth century ${ }^{16}$. Although still in its infancy, nanomedicine is likely to have a substantial role in the management of cardiovascular disease in general - atherosclerosis in particular. Given the range of applications of nanomedicine, this Review mainly focuses on targeted therapy and in vivo imaging of atherosclerosis with injectable nanoparticulate agents and microparticles with diameters of up to $\sim 300 \mathrm{~nm}$, as from a practical point of view even structures with diameters of up to $500 \mathrm{~nm}$ have been classified as nanomedical compounds. Targeting strategies for atherosclerosis are outlined and related to lessons learned from tumour targeting. In addition, an overview of recent accomplishments and future applications is provided, and the clinical applicability and indications of nanomedicine in atherosclerosis are discussed.

\section{Key processes in atherosclerosis development}

With the advent of preventive medicine, secondary-prevention medication and revascularization by interventional procedures, such as balloon angioplasty and drugeluting stents, considerable advances have been made in the treatment of atherosclerosis ${ }^{17}$. Yet, atherosclerosis remains the major cause of morbidity and mortality in the field of cardiovascular disease, and represents a substantial economic burden ${ }^{18}$. Atherosclerosis can cause clinical complications such as angina pectoris, limb ischaemia, renal impairment and hypertension. However, the most severe complications arise from ruptured atherosclerotic plaques in coronary arteries, which account for $\sim 70 \%$ of fatal acute myocardial infarctions and/or sudden coronary deaths, and plaque rupture in carotid arteries, which causes ischaemic stroke ${ }^{19}$. 
The build-up of an atherosclerotic plaque starts at lesion-prone areas in large and mediumsized arteries where the endothelium is dysfunctional, induced by cardiovascular risk factors such as chronic smoking, hypertension and chronic hypercholesterolaemia ${ }^{20,21}$.

Dysfunctional endothelium is a crucial pathophysiological factor in atherosclerosis, causing increased permeation of macromolecules such as lipoproteins, increased expression of chemotactic molecules (for example, monocyte chemotactic protein 1) and adhesion molecules (for example, intercellular adhesion molecule 1 (ICAM1) and vascular cell adhesion molecule 1 (VCAM1), as well as E-selectin and P-selectin), and enhanced recruitment and accumulation of monocytes ${ }^{21}$. These monocytes subsequently differentiate into macrophages, which can then be transformed into foam cells by ingesting apolipoprote in B (APOB)-containing low-density lipoprotein (LDL). Subendothelial retention of lipoproteins and immune cells in the vessel wall comprises the first stage of atherosclerosis. The retention of lipoproteins and immune cells either diminishes as a result of the resolution of inflammation, or it results in plaque progression, cell apoptosis and neovascularization over a period of several years or decades ${ }^{22,23}$. Advanced atherosclerotic lesions may eventually contain a large volume of lipids and necrotic cells, referred to as the lipid or necrotic core.

In normal vessels the vasa vasorum supplies nutrients to the outer component of the vessel wall, and nutrients are supplied to the intima by their diffusion from the lumen. As an atherosclerotic plaque develops, the intima becomes thicker and, once the distance between the deep layers of the intima and the luminal surface exceeds the oxygen diffusion threshold, local hypoxia occurs. This induces neovascularization as a compensatory defence mechanism to restore nutrient supply to the vessel wall ${ }^{24,25}$. The microvessels that arise from neovascularization originate from the vasa vasorum in the adventitia and extend into the base of the plaque (FIG. 1a). Plaque neovascularization has been correlated with inflammation, thereby promoting plaque progression, and it may even contribute to plaque rupture as it facilitates cellular trafficking and the recruitment of immune cells through the vasa vasorum ${ }^{25}$. Plaque neovessels are fragile structures that are also prone to leakage and rupture, probably because of the lack of mural cells and poorly formed endothelial cell junctions ${ }^{26}$.

The wall of the artery is remodelled during the development of an atherosclerotic lesion. It is either remodelled outwards to allow the continuation of blood flow to distal organs or remodelled inwards causing stenosis and thereby limiting blood flow, which can lead to tissue ischaemia. Atherosclerotic plaques can rupture as a result of the breakdown of the fibrous cap that covers the lipid core via inflammatory processes, which can consequently lead to thrombotic occlusions and clinical events ${ }^{27,28}$. Lesions that are most susceptible to rupture are characterized by active inflammation, thin fibrous caps with large lipid cores, endothelial denudation with superficial platelet aggregation, fissured plaques or luminal stenosis exceeding $90 \%{ }^{19}$. Most occlusions that cause acute coronary syndromes do not result from lesions with severe stenosis; rather, they arise from non-stenotic lesions that are also referred to as vulnerable plaques ${ }^{29}$. The identification and treatment of such ruptureprone plaques in patients before clinical events occur would result in substantial health benefits.

\section{Nanoparticle targeting in atherosclerosis}

The processes described above and their accompanying molecular and cellular events create numerous opportunities for targeting the atherosclerotic plaque using nanoparticles. Interestingly, many of these processes also occur in cancer as most of them are inflammation-related, including hypoxia-induced neovascularization, endothelial dysfunction, permeability of the microvasculature and the upregulation of adhesion 
molecules to facilitate the recruitment of cells ${ }^{30,31}$. Generally speaking, the key targeting principles in cancer can be divided into nonspecific targeting (through the enhanced permeability and retention effect) and active vascular or tumour cell targeting (using functionalized nanoparticles) $)^{32,33}$.

The enhanced permeability and retention effect has been thoroughly investigated since it was first reported in 1986 (REF. 34). Normal vascular physiology results in tight $(<2 \mathrm{~nm})$ endothelial junctions, which will restrict nanoparticle distribution, whereas a dysfunctional endothelium leads to large gaps that allow macromolecules and nanoparticles to extravasate from the bloodstream at local sites and remain retained locally owing to impaired lymphatic drainage ${ }^{35,36}$. However, some investigators have started questioning the validity of this phenomenon, and have proposed that the accumulation of nanoparticles may be the result of a different process.

Although it has never been thoroughly investigated in atherosclerosis, nonspecific targeting can be exploited owing to the previously mentioned permeability of the luminal endothelium, as well as the microvascular permeability and leakiness of the neovessels of the vasa vasorum ${ }^{37}$. In addition, intravenously injected nanoparticles may associate with circulating cells or cells in the spleen that subsequently migrate to areas of inflammation. This observation has been reported in the setting of inflammation related to stroke and myocardial infarction, and may also occur in atherosclerosis ${ }^{38}$.

By attaching antibodies, proteins, peptides or other ligands to its surface, a nanoparticle can be targeted to single or multiple receptors that are expressed on the surface of (or inside) a tumour or an atherosclerotic plaque ${ }^{39}$. For example, vascular targeting can be accomplished using nanoparticles that have been functionalized with specific ligands to adhesion molecules such as VCAM1, selectins or integrins such as aV 33 integrin, as these adhesion molecules are expressed on the activated endothelium of the luminal wall ${ }^{40}$ or on the endothelium of newly formed microvessels ${ }^{20}$. Once the nanoparticle is attached to the specific receptor being targeted, it can either bind to endothelial cells or become internalized, depending on the receptor that is targeted and the properties of the nanoparticle used, such as its size ${ }^{41}$.

In addition, the range of cellular and non-cellular components within plaques, such as the extracellular matrix and lipids, allow for specific targeting of plaques with functionalized nanoparticles ${ }^{42,43}$. Various research groups have established that using functionalized nanoparticles does not enhance the percentage of the injected dose of the nanoparticle that reaches the specific lesion, but it does allow for better distribution of the nanoparticle among pathological lesions and increases its internalization by targeted cells ${ }^{44,45}$. Therefore, it can be concluded that the physicochemical properties of nanoparticles will largely determine their biodistribution (BOX 1), although the presence of targeting ligands can substantially enhance intracellular uptake, which can increase therapeutic activity. Although this is a form of active targeting, nanoparticle accumulation (at the diseased site) is primarily dependent on vascular permeability as the nanoparticle must first extravasate from the circulation.

Specific nanoparticle accumulation can also be accomplished via inherent targeting of natural nanoparticles. Lipoproteins, including high-density lipoprotein (HDL) and LDL, interact with plaques through a natural conduit. Exploiting or mimicking this inherent plaque affinity of lipoproteins has been shown to be a powerful approach for targeting plaques effectively.

Within the key plaque-targeting mechanisms outlined above and summarized in FIG. 1, the distribution of nanoparticles will vary considerably at the cellular level. Nanoparticles with a long circulating half-life will extravasate or accumulate in the plaque by nonspecific 
targeting and will be subsequently sequestered by macrophages within the plaque (FIG. 1a). Nanoparticles that target the activated endothelium, however, are mostly prone to stay confined to the vasculature ${ }^{46}$ (FIG. 1b) but they have also been observed to extravasate and target cells within the plaque ${ }^{47}$, similarly to nanoparticles that specifically target components of the plaque (FIG. 1c).

In addition to the targeting methods described above, the formation of a blood clot in an artery allows a thrombus to be targeted using nanoparticles. Thrombi are easily accessible and express a rich variety of cellular and molecular components.

The different processes, markers and cells that have been targeted with nanoparticles are summarized in TABLE 1 . When relating these targeting principles to cancer, there is a considerable difference; cancer is commonly a focal disease, whereas atherosclerosis is a systemic vascular disease that develops at various sites throughout the body simultaneously. This further motivates the development of specific agents that efficiently target atherosclerotic lesions following their intravenous administration.

\section{Nanoparticle therapeutics in atherosclerosis}

The substantial residual risk of atherothrombot ic events that remains after current optimum medical therapy has led to the pursuit of novel therapeutic strategies or adjunct therapies $^{48}$, some of which are discussed below.

\section{Modulating HDL levels}

One of the main therapeutic targets in atherosclerosis is HDL, which is an endogenous lipidic nanoparticle (7-13 nm in size), as there is an inverse relationship between serum HDL levels and the risk of coronary heart disease ${ }^{49,50}$. HDL is believed to protect against cardiovascular disease primarily through reverse cholesterol transport, moving cholesterol from peripheral cells (particularly lipid-laden plaque macrophages) to the liver, and additionally through the modulation of inflammation ${ }^{51}$. The function and cholesterol efflux capacity of HDL are the crucial factors associated with its atheroprotective effects ${ }^{52}$, as indicated in a meta-analysis that showed that simply increasing serum HDL levels does not necessarily reduce the risk of cardiovascular events ${ }^{53}$.

Among the various approaches of modulating HDL, direct infusions with recombinant HDL (rHDL) particles and augmenting APOA1 levels have been shown to be the most promising strategies $^{54}$. APOA1 is the major protein component of HDL and has a vital role in facilitating reverse cholesterol transport. HDL infusions administered on a weekly basis have shown compelling results in rabbit models, resulting in the inhibition of aortic fatty streaks and lipid deposition in the atherosclerotic wall or the regression of atherosclerotic plaques $^{55,56}$. Intravascular infusion of rHDL containing a genetic variant of $A P O A 1$, $A P O A 1_{\text {Milano }}$ (also known as ETC-216), has resulted in a multitude of beneficial effects by reducing the lipid and macrophage content of plaques, reversing endothelial dysfunction, inhibiting the progression of atherosclerosis and inducing rapid regression of atherosclerosis in animal models ${ }^{57-61}$. These studies led to the use of a formulation of ETC-216 in a randomized clinical trial (with a small sample size) in patients with acute coronary syndromes; five weekly doses of the formulation resulted in a statistically significant regression of coronary atherosclerosis measured by serial intravascular ultrasound examinations ${ }^{62,63}$ (FIG. 2a).

The aforementioned studies exemplify that short-term rHDL infusions may lead to rapid plaque regression or inflammatory changes in acute coronary or peripheral artery disease. Nevertheless, there are serious drawbacks associated with the use of rHDL as it is expensive 
to synthesize, intravenous administration is required and mass production is difficult to achieve. As an alternative, APOA1 mimetics have been created for chronic treatment; these mimetics can be orally administered and may be beneficial in high-risk patients with cardiovascular disease who are taking statins as standard of care ${ }^{64,65}$.

In addition to reverse cholesterol transport and the modulation of inflammation, Vickers et $a l .{ }^{66}$ have demonstrated that native HDL is involved in more complex intracellular communications such as the transportation of endogenous microRNAs and their delivery to recipient cells. Prior to this discovery, rHDL had already been identified as a carrier for drugs ${ }^{67}$, small interfering RNAs (siRNAs) ${ }^{68}$, nucleic acids ${ }^{69}$ and nanocrystals ${ }^{70}$. Owing to the endogenous nature of rHDL, it is biodegradable and evades immunological responses as well as the mononuclear phagocyte system.

Biomimetic HDL nanoparticles incorporating gold nanocrystals (Au-HDL) and iron oxide (FeO-HDL) have biophysical features that closely resemble those of native HDL, and have similar cholesterol binding and cholesterol efflux capabilities ${ }^{71,72}$. These nanoparticles can be used for diagnostic imaging, as discussed below. Moreover, lipoproteins can be chemically modified and rerouted to alternative receptors by conjugating targeting moieties to their surface ${ }^{73}$.

\section{Lowering LDL levels}

Elevated APOB and LDL levels are associated with an increased risk of coronary artery disease. Large clinical trials investigating the effects of intensive LDL lowering with statins have demonstrated a substantial benefit over standard-dose statin therapy for preventing non-fatal cardiovascular events ${ }^{74}$. However, based on the results of the SEARCH (Study of the Effectiveness of Additional Reductions in Cholesterol and Homocysteine) trial the US Food and Drug Administration has announced new safety recommendations for high-dose simvastatin treatment owing to an associated elevated risk of muscle injury or myopathy ${ }^{75}$. Furthermore, despite the use of high-dose statin therapy, LDL levels may not be adequately lowered in a subset of high-risk patient populations. A rapid reduction in LDL levels and silencing of $A P O B$ mRNA expression could lead to a new LDL-lowering therapeutic strategy in combination with other lipid-lowering therapeutics such as statins.

Liposomes can be used to carry hydrophilic drugs to sites of interest (BOX 2). In nonhuman primates, a single injection of liposome-encapsulated siRNA silences $A P O B$ mRNA expression in the liver and reduces levels of the APOB protein, serum cholesterol and LDL in the bloodstream as early as 24 hours after treatment ${ }^{76}$ (FIG. 2b). A downside of using siRNA, however, is the potential induction of an immunogenic response. Therefore, considerable effort has been made to reduce the siRNA payload by developing different lipid formulations for delivery, which has so far led to a tenfold or even 100-fold reduction in the dose of siRNA administered to different models ${ }^{77,78}$.

\section{Anti-inflammatory therapy}

The recognition of the role of inflammation in atherosclerosis has led to the formulation of anti-inflammatory drugs tailored to atherosclerosis, several of which are currently under investigation in clinical trials ${ }^{79,80}$. Corticosteroids have anti-inflammatory effects in atherosclerosis, although they are not considered for long-term administration owing to a poor pharmacokinetic profile and adverse side effects ${ }^{79,81}$. However, the injection of a single intravenous dose of glucocorticoid-encapsulated liposomes conjugated to polyethylene glycol (PEG) in atherosclerotic rabbits led to a statistically significant reduction in the surrogate inflammatory marker, the ${ }^{18} \mathrm{~F}$-fludeoxyglucose $\left({ }^{18} \mathrm{~F}-\mathrm{FDG}\right)-\mathrm{PET}$ signal (FIG. 3a), in atherosclerotic lesions just 2 days after treatment ${ }^{82}$. 
As with HDL, this formulation may provide a rapid anti-inflammatory response in patients who are in need of short-term therapy after an acute coronary event or in patients with severe atherosclerotic risk factors who have not received long-term risk-reduction therapy. Histopathological studies have shown that patients dying from acute myocardial infarction have widespread inflammation not only in culprit plaques but also in plaques within other major coronary arteries ${ }^{83}$.

Alternatively, McCarthy et al..$^{84}$ injected a near-infrared light-activated nanoparticle based on dextran-coated iron oxide into APOE-knockout mice for targeted macrophage ablation. After allowing the particles to accumulate in plaques for 24 hours, the carotid arteries were surgically exposed and the particles were imaged by intravital fluorescence microscopy and subsequently irradiated with $650 \mathrm{~nm}$ laser light to excite the photosensitizer. The carotid arteries were histologically examined after 24 hours, and showed extensive macrophage cell death and apoptosis in plaques.

\section{Antirestenotic therapy}

Restenosis after angioplasty and stent implantation has been a considerable problem following the revascularization of coronary lesions. Drug-eluting stents are now the mainstay of therapy after the revascularization of a coronary lesion, as they dramatically reduce the rate of restenosis compared to bare-metal stents. Nevertheless, in-stent restenosis can still occur in 3-20\% of patients, and not all coronary lesions are suited for revascularization with drug-eluting stents ${ }^{85}$. Another issue with the use of drug-eluting stents is the increased risk of late-stent thrombosis owing to poor re-growth of the endothelial cells lining the stents after implantation or endothelial dysfunction ${ }^{6}$. This complication can prove to be fatal, therefore patients receiving a drug-eluting stent implant are required to take extended antiplatelet therapy ${ }^{87}$. Autopsy cases show that atherosclerotic changes occur in both drug-eluting stent and bare-metal stent implantation, which may also contribute to these late-stage thrombotic events ${ }^{88}$.

The use of nanoparticle formulations might be beneficial in combination with bare-metal stents in patients with a high risk of in-stent restenosis without the risk of delayed endothelial healing and subsequent thrombosis. Patients who are unsuited for drug-eluting stent implantation and antiplatelet therapy may also benefit from nanoparticle therapy. For example, a liposomal formulation containing the bisphosphonate clodronate was used to deplete monocyte levels, thereby reducing neointimal proliferation after balloon injury in rats and rabbits ${ }^{89}$. In a follow-up study, hypercholesterolaemic rabbits were injected with a single dose of liposomal alendronate (a more potent bisphosphonate than clodronate), concurrent with stent implantation, which resulted in reduced in-stent neointimal formation and arterial stenosis ${ }^{90}$ (FIG. 2c). This formulation is currently being tested in a Phase II clinical trial to assess its safety and efficacy in the treatment of stenotic lesions in coronary arteries in a patient population undergoing implantation of a bare-metal stent (ClinicalTrials.gov identifier: NCT00739466).

Joner et al. ${ }^{91}$ used a different approach, whereby prednisolone phosphate was encapsulated in PEG-conjugated liposomes that were specifically designed to target the vascular subendothelial matrix. The use of systemic treatment with glucocorticoids has also been researched in combination with bare-metal stent implantation, and despite initial unsatisfactory results there has been renewed interest in this approach, with improved eventfree survival observed after 1 year in selected patients ${ }^{92}$.

Other nanoparticle formulations that have been proposed to prevent restenosis after stent implantation include: albumin-stabilized nanoparticles containing paclitaxel ${ }^{93}$; micellar doxorubicin $^{94}$; virus-mediated transfer of siRNA ${ }^{95}$; lysine-based nanoparticles delivering 
siRNA ${ }^{96}$; perfluorocarbon nanoparticles containing doxorubicin or paclitaxel that target vascular smooth muscle cells ${ }^{97} ; \mathrm{aV} \beta 3$ integrin-targeted perfluorocarbon nanoparticles containing rapamycin ${ }^{98}$; collagen-targeted slow-eluting nanoparticle formulations of paclitaxe $^{99}$ (FIG. 2d); ETC-216 formulations ${ }^{100}$; and innovative nanoparticle-eluting stents $^{101}$.

Polyak et al. ${ }^{102}$ used an alternative method to address delayed endothelial healing. Rats with stainless steel stents in their carotid arteries were intra-arterially injected with superparamagnetic nanoparticles that were preloaded into endothelial cells, making these cells magnetically responsive. The rats were subsequently exposed to a homogenous magnetic field that showed a high uptake of cells within the area implanted with the stents, thus representing a novel strategy for the site-specific delivery of a cell-based therapy ${ }^{102}$ (FIG. 3b). In a follow-up study using the same experimental setup, the group used magnetic nanoparticles loaded with paclitaxel for local delivery, and they observed a substantial reduction in restenosis with low doses of paclitaxel ${ }^{103}$.

\section{Anti- and pro-angiogenic therapy}

Anti-angiogenic agents are another drug class currently under investigation for the stabilization of atherosclerotic plaques ${ }^{26,104}$. Small-molecule drugs like the fumagillin analogue TNP-470, endostatin or angiostatin reduced plaque angiogenesis and inhibited advanced atherosclerosis in APOE-knockout mice after prolonged treatment for 16 weeks ${ }^{105,106}$. A team led by Wickline and Lanza ${ }^{107}$ has shown that a single injection of aV 33 integrin-targeted paramagnetic nanoparticles for site-specific delivery of the antiangiogenic drug fumagillin is enough to inhibit angiogenesis in a rabbit model. In a followup study the same group demonstrated that these nanoparticles decreased the burden of aortic angiogenesis for 3 weeks after treatment and that this effect was prolonged when applied in combination with oral atorvastatin (Lipitor; Pfizer) administration. This was determined using $\alpha \mathrm{V} \beta 3$ integrin-specific MRI, thus representing a potential strategy for an anti-angiogenic therapeutic regimen ${ }^{107,108}$ (FIG. 3c).

In contrast to the anti-angiogenic therapies discussed above, therapeutic angiogenesis aims to promote the formation of new blood vessels in ischaemic tissues by genetically stimulating vascular endothelial growth factor (VEGF) expression, for example, which could prove to be useful in the treatment of limb ischaemia in peripheral artery disease and post-myocardial infarction. Several clinical trials have addressed the efficacy of therapeutic angiogenesis with adenoviral or lipid-based transfection of VEGF, but have not yet shown any clinically relevant positive effects - this has been mainly attributed to a low efficiency of gene transfer ${ }^{109,110}$. There are ongoing efforts to improve gene transfer, including the use of nanoparticle conjugates of VEGF ${ }^{111}$ (FIG. 3d). A major disadvantage of this approach, as can be deduced from the build-up of atherosclerotic plaques, might be that these nanoparticles accumulate in the plaques, thus contributing to neovascularization and thereby advancing plaque accumulation ${ }^{112}$.

\section{Anticoagulant therapy}

Thrombus formation occurs following the rupture of an atherosclerotic plaque. However, this does not always cause clinical symptoms, as occult clotting can also take place. Anticoagulants can reduce the formation and expansion of these blood clots. Peters et al. ${ }^{113}$ used micelles to target fibrin deposited on the luminal surface of atherosclerotic plaques and deliver the anticoagulant drug bivalirudin (Hirulog; Biogen Idec). The micelles were mainly concentrated at the rupture-prone region of the plaque and showed considerable antithrombin activity. The authors propose that this platform has the potential to reduce clotting tendency in plaques, and may reduce the risk of thrombus formation following 
plaque rupture ${ }^{113}$. Nanoparticles designed to induce acute thrombolysis of thrombotic occlusions caused by ruptured plaques are also under development ${ }^{114,115}$.

\section{Atherosclerosis - imaging and nanomedicine}

Traditionally, clinical investigations that were used to detect atherosclerotic plaques focused on the degree of stenosis in the blood vessel lumen. However, with the advent of the concept of vulnerable plaques, the early 1990s marked a change in the understanding of the underlying pathophysiology of atherosclerosis in relation to plaque instability. This resulted in a shift towards visualizing plaque morphology and biology using novel imaging techniques, either stand-alone or - more recently — combined ${ }^{116}$. Developments in the field of molecular imaging allow the characterization of biological processes in cardiovascular disease at the cellular and molecular level ${ }^{117}$. This approach heavily relies on the development and application of contrast-loaded probes - often nanoparticles - that are specifically designed to target cell types and epitopes of interest.

\section{Nanoparticle-associated imaging applications}

Molecular imaging allows the study of subclinical plaque inflammation and other cellular processes in atherosclerosis, as well as neovascularization and enzymatic activity ${ }^{118,119}$. Nanoparticles can also be useful for probing mechanisms of uptake in atherosclerotic cells, thereby obtaining new biological insights ${ }^{120}$, whereas imaging techniques themselves can advance the development of nanoparticles (BOX 3; FIG. 4). The complementary features of certain imaging modalities have motivated the development and application of multimodality contrast agents - nanoparticles in particular — as they allow the facile incorporation of several types of contrast-generating material within the same probe ${ }^{121}$. Validation of targeting is an important motive for the development of multimodal nanoparticle contrast agents, as it allows the detection of the nanoparticle by imaging on clinical scanners and by ex vivo techniques - including confocal microscopy and flow cytometry for nanoparticles possessing a fluorochrome. This not only enables confirmation of nanoparticle accumulation in targeted tissues but also the investigation of their cellular fate $^{122}$.

Besides diagnosing subclinical atherosclerosis, nanoparticles carrying contrast-generating material can be used to track drug delivery or enable the quantification of expression of cellular markers after treatment. Many of the studies using the nanoparticle therapeutics discussed above make use of these possibilities $82,84,97,98,102,107,111$. This type of approach enables a sensitive readout of an early response to therapeutic activity before the onset of changes in atherosclerotic plaque size. This can be especially valuable for early phase clinical trials, providing insight into functional changes and dose response.

\section{Nanoparticle-enhanced imaging}

Nanoparticle probes targeting atherosclerotic lesions have been developed for MRI, CT, PET and SPECT imaging, as well as ultrasound and optical techniques. MRI and CT are excellent techniques for macroscopically depicting atherosclerotic plaques in a non-invasive manner, and are continually being improved for the purpose of accurately assessing plaque size and composition ${ }^{123,124}$. MRI is recognized as a technique that excels in visualizing different components of the plaque, including the fibrous cap and lipid core, whereas CT allows the visualization of calcifications. Recent developments in contrast-enhanced coronary CT angiography allow the detection of positive remodelling, increased plaque volumes and lipoprotein deposition in non-calcified plaques ${ }^{124}$. For molecular imaging purposes both techniques were initially considered to lack sufficient sensitivity for the detection of exogenously administered molecular imaging agents, but with the rise of new 
and potent nanoparticulate agents MRI and CT are increasingly being explored for this purpose $^{119}$.

\section{MRI}

Most nanoparticulate probes, such as gadofluorine M (FIG. 5a), are still in the experimental phase $^{125}$. However, some nanoparticles - for example, ultrasmall superparamagnetic particles of iron oxide (USPIOs) - have been recognized as MRI contrast agents for the imaging of plaque inflammation in patients. USPIOs are phagocytosed by macrophages in atherosclerotic plaques, thereby causing iron oxide-associated MRI signal loss, which was first reported in a rabbit model ${ }^{126}$ (FIG. 5b). Macrophages in atherosclerotic plaques account for the majority of leukocytes and inflammation in plaques, and are implicated in plaque rupture, thereby representing an important target ${ }^{127}$.

In the first clinical study of USPIOs, 11 patients who were scheduled for carotid endarterectomy before and after the injection of USPIOs had a $24 \%$ decrease in signal intensity in their carotid arteries after USPIO injection ${ }^{128}$. Another study demonstrated that USPIO-enhanced MRI can identify plaque inflammatory status and plaque stability in carotid arteries (FIG. 5c). Twenty patients per group were randomized for treatment with either high-dose ( $80 \mathrm{mg}$ per day) or low-dose (10 $\mathrm{mg}$ per day) atorvastatin, and these patients were serially imaged at 6 and 12 weeks. A substantial reduction in plaque inflammation from the baseline was observed at both time points in the high-dose group; by constrast, there was no reduction from the baseline in the low-dose group ${ }^{129,130}$. In comparison, morphological high-resolution MRI is only able to detect substantial changes in lesion characteristics after a minimum of a year of high-dose statin treatment ${ }^{131}$, demonstrating that USPIO-enhanced MRI may be useful as an imaging biomarker to detect inflammatory changes before morphological changes occur.

A multitude of specific MRI contrast agents have been developed, targeting various markers and stages in atherosclerosis. These include fibrin-targeted paramagnetic nanoemulsions that detect thrombi in fissures of vulnerable plaques ${ }^{132}$, nanoemulsions functionalized to detect plaque neovascularization ${ }^{133}$ (FIG. 5d) or VCAM1-targeted iron oxides for early detection of atherosclerotic disease ${ }^{47}$. In addition to vascular targets, extravascular plaque markers have been studied by molecular MRI. For example, macrophages and oxidized LDL have been targeted using immunomicelles ${ }^{43,134}$, and apoptosis has been studied using annexin A5-functionalized nanoparticles ${ }^{135}$.

HDL can be modified by incorporating contrast labels such as $\mathrm{Gd}^{3+}$ in the phospholipid coating. Such modifications allow the imaging of macrophages within atherosclerotic plaques $^{136}$ (FIG. 5e). Follow-up studies have provided the ability to image atherosclerotic plaques using not only MRI but also CT and optical techniques. This has been achieved by incorporating gold nanocrystals, iron oxides or quantum dots into the hydrophobic core of HDL, as well as by using contrast agent labels in the coating of the nanoparticles ${ }^{137}$. Modified HDL has also been exploited to probe lipoprotein-lipoprotein interactions ${ }^{138}$.

\section{CT}

Owing to the long acquisition times of MRI, as well as cardiac and respiratory motion, it is inherently difficult to perform coronary imaging using MRI techniques. On the contrary, CT coronary angiography is widely used in the clinical setting and can be used to acquire images within a matter of seconds; however, it is less sensitive for the visualization of contrast-generating material than MRI. The X-ray contrast agents in clinical use are iodinated small molecules, which require very short imaging times owing to their rapid clearance by the kidney. The use of nanoparticles for X-ray contrast-enhanced imaging is 
largely unexplored but has seen a considerable increase in the past 5 years. This was first attempted by creating blood-pool agents that are used for angiography. Because of their long circulatory half-life, these agents remain visible within the vasculature for prolonged periods of time and can therefore suffice for multiple imaging acquisitions ${ }^{139,140}$. Hyafil et al. ${ }^{141}$ published the first example of CT-based molecular imaging using iodinated nanoparticles for the detection of macrophages in a rabbit model of atherosclerotic plaques, showing a marked signal enhancement 2 hours after injection of the iodinated nanoparticles (FIG. 5f). A disadvantage of this approach, however, is the necessity of a baseline scan, subjecting the patient to a double dose of radiation and requiring pre- and post-scan image comparison.

A new multicolour $\mathrm{CT}$ technique, using photon-counting detectors, can discriminate between different contrast agents and endogenous radiopaque structures such as bone and calcified plaques. A gold-core version of the nanocrystal HDL platform mentioned above, which was previously shown - using MRI — to accumulate in plaques ${ }^{137}$, and an iodinebased blood-pool agent were injected simultaneously into APOE-knockout mice and clearly showed that multicolour CT imaging allows the identification of macrophage-rich atherosclerotic lesions ${ }^{142}$ (FIG. 6a). In a study by a different group, multicolour CT imaging was applied to visualize thrombi with fibrin-targeted bismuth nanocolloids in rabbit models of atherosclerosis ${ }^{143}$.

\section{PET and SPECT}

Both MRI and CT imaging require large amounts of contrast agent — up to millimolar concentrations - to accumulate at the site of interest and generate an image contrast in tissue. Nuclear imaging techniques such as PET and SPECT, however, are much more sensitive and can detect molecular targets within the picomolar range. However, a major disadvantage of these imaging modalities is the lack of anatomical information, so they are commonly used in combination with CT and, recently, MRI.

${ }^{18} \mathrm{~F}-\mathrm{FDG}$ is increasingly being used in combination with PET-CT as a metabolic marker for the quantification of arterial inflammation in the aorta as well as the carotid, iliac and femoral arteries. Applying this technique in coronary arteries is challenging, as ${ }^{18} \mathrm{~F}-\mathrm{FDG}$ accumulates in the metabolically active myocardium as well ${ }^{144}$. To detect different aspects of atherosclerotic disease more specifically, various radioactive tracers have been developed ${ }^{145-147}$. A disadvantage of these low-molecular-weight agents is their rapid clearance or metabolism. However, nanoparticles can exhibit favourable pharmacokinetics and plaque targeting, and therefore may serve as valuable tracers for nuclear imaging. For example, Nahrendorf et al. ${ }^{148}$ labelled iron oxide nanoparticles with the radiolabelled PET tracer ${ }^{64} \mathrm{Cu}$, showing the accumulation of the nanoparticles in atherosclerotic arteries of APOE-knockout mice using PET-CT imaging (FIG. 6b). Several other variations of this probe have been developed, including probes used for hybrid PET-optical imaging or even trimodal imaging ${ }^{149}$. Nuclear imaging has also been used to visualize angiogenesis in a hindlimb ischaemia murine model by injecting ${ }^{76} \mathrm{Br}$-labelled aV 33 integrin-targeted dendrimers ${ }^{150}$. The long circulating half-life of radiolabelled nanoparticles warrants extensive toxicity studies before their translation into clinical medicine owing to the risks associated with prolonged exposure to radioactive material.

\section{Optical imaging}

Fluorescence molecular tomography, in combination with high-resolution CT angiography, was used to image proteases that can degrade the fibrous cap, using an inactivated fluorochrome-labelled peptide that was conjugated to a polymeric nanoparticle with an iron oxide core (FIG. 6c). When encountering an active protease the peptide is cleaved, thereby emitting fluorescence signals that allow the detection of the probe ${ }^{151}$. Various other optical 
imaging techniques for the molecular imaging of atherosclerosis are being explored, such as photo-acoustic imaging, fluorescence, absorption and Raman spectroscopy, optical coherence tomography, and bioluminescence ${ }^{152}$. Owing to the deep location of most of the affected arteries, there are limitations to the use of optical techniques and ultrasound imaging in cardiovascular disease, as it is considerably difficult for these techniques to penetrate deep tissue. Therefore, imaging centrally located blood vessels with optical techniques and ultrasound has necessitated the development of invasive catheter-based imaging systems ${ }^{153}$. Nevertheless, nanoparticle-targeted imaging using transvascular ultrasound has been deemed possible ${ }^{154}$. The echogenicity for effective ultrasound-mediated imaging favours the use of probes that are larger than nanoparticles, including microbubbles and larger liposomes that are $500-800 \mathrm{~nm}$ in size ${ }^{155}$.

\section{Clinical perspectives and limitations}

The development of nanoparticulate agents for the detection and treatment of atherosclerotic disease will continue to evolve as the understanding of the molecular pathogenesis of the disease advances ${ }^{156}$. Nanoparticle agents represent a potent alternative to small-molecule agents owing to their improved bioavailability and the ability to specifically target processes. However, the properties that enable these advantages create limitations, as certain nanoparticulate agents can exhibit limited diffusibility in addition to toxic, immunostimulatory and immunosuppressive properties. They can also be retained in the body for an extended period of time, requiring extensive toxicological studies before their successful translation into the clinical setting ${ }^{157}$. Those nanoparticulate agents that have reached the clinic have shown substantial benefits over small-molecule formulations, and the agents that are most likely to be developed for clinical use in the future are either completely biodegradable or they have small hydrodynamic diameters to facilitate fast renal clearance $^{158}$.

It is likely that the use of combined therapeutic and diagnostic nanoprobes will be mostly limited to preclinical models for investigating the localization and efficacy of the nanoparticles. Imaging of drug delivery can be useful but it is not necessary to administer diagnostic labels each time a patient receives treatment.

Unfortunately, many of the exciting preclinical findings with nanoparticles in animal models of atherosclerosis have not progressed from the developmental phase, as is often the case in drug development. One of the major reasons for this is the accelerated development of atherosclerosis in animal models, thereby creating atherosclerotic lesions with different properties to those found in humans ${ }^{159}$. Another issue is the variability between different animal models, including diets and methods of inducing atherosclerosis, illustrating the need for the standardization of animal models of atherosclerosis ${ }^{160}$. These limitations are among the reasons that have motivated several groups to issue recommendations for accelerating the translation of nanoparticles into the clinic ${ }^{158,161,162}$. Nevertheless, the use of nanoparticles in cardiovascular disease has led to a better understanding of atherosclerosis, the role of imaging and the evaluation of pharmacotherapy ${ }^{163}$.

Most of the nanoparticulate applications described above are limited to the acute phases of atherosclerosis (BOX 4). In the chronic phase of the disease and in the prevention of plaque build-up, the injection of nanoparticles for prolonged periods of time is unrealistic and impractical as the disease may remain asymptomatic. Screening for asymptomatic atherosclerotic lesions to prevent future plaque rupture has not been proven to be beneficial in patients, but it is hoped that the accurate identification of patients with an impending risk of cardiovascular events can be achieved using new blood or imaging biomarkers ${ }^{164}$. The use of nanotechnology in cardiovascular disease is certainly not restricted to the injectable 
nanoparticulate agents that have been described here for the treatment of atherosclerosis. Nanotechnology can have a role in stent design ${ }^{165}$, tissue engineering ${ }^{166}$ and early-detection techniques ${ }^{167}$, but it may also have additional applications in myocardial infarction ${ }^{168}$, aortic aneurysms ${ }^{169}$, thrombolytic therapy ${ }^{170}$, ablation therapy for atrial fibrillation ${ }^{171}$ and other cardiovascular disorders.

Nanomedicine holds promise as a type of personalized medicine for the management of cardiovascular disease in general, particularly the target-specific treatment and imaging of atherosclerotic disease. The continuous discovery of new molecular targets, our improved understanding of the pathophysiology of atherosclerosis, as well as ongoing developments in nanoparticle synthesis methods and imaging technologies will aid in the prevention and treatment of this disease.

\section{Acknowledgments}

We gratefully acknowledge D. P. Cormode for discussions and recommendations. Support for this work was partially provided by the International Atherosclerosis Society (M.E.L). This work was supported by the National Heart, Lung, and Blood Institute (NHLBI) and the US National Institutes of Health (NIH), as a Program of Excellence in Nanotechnology (PEN) Award (Contract no. HHSN268201000045C), as well as by the NIH grants R01 EB009638 (Z.A.F.) and R01 CA155432 (W.J.M.M.).

\section{Glossary}

\section{Atherosclerosis \\ Drug-eluting stents}

Apolipoprotein

Vasa vasorum

Stenosis

Atherothrombotic events

Reverse cholesterol transport

Mononuclear phagocyte system

${ }^{18}$ F-FDG
A chronic systemic inflammatory disease in which the arterial wall thickens as a result of the accumulation of fatty material within the vessel wall.

Stents that are typically coated with antiproliferative or immunosuppressive drugs for local release to prevent restenosis within the stent.

The protein constituent of lipoproteins that provides cell specificity and is essential for their structural integrity.

A microvascular network that supplies larger blood vessels with nutrients.

Luminal narrowing of a blood vessel.

Clinical events such as myocardial infarction or stroke that are the result of atherosclerotic plaque disruption with superimposed thrombosis.

Transport of cholesterol from peripheral cells to the liver for excretion.

A branch of the immune system that consists of phagocytic cells that can remove macromolecules from circulation.

A radioactive glucose analogue that is taken up by metabolically active cells, and is frequently used for molecular imaging in combination with positron emission tomography.

\section{References}

1. Moghimi SM, Hunter AC, Murray JC. Nanomedicine: current status and future prospects. FASEB J. 2005; 19:311-330. [PubMed: 15746175] 
2. Wagner V, Dullaart A, Bock AK, Zweck A. The emerging nanomedicine landscape. Nature Biotech. 2006; 24:1211-1217.

3. Kim BY, Rutka JT, Chan WC. Nanomedicine. N. Engl. J. Med. 2010; 363:2434-2443. [PubMed: 21158659]

4. Nagarajan, R.; Hatton, TA., editors. Nanoparticles: Synthesis, Stabilization, Passivation, and Functionalization. American Chemical Society; Washington DC: 2008. p. 2-14.

5. Mulder WJ, et al. Nanoparticulate assemblies of amphiphiles and diagnostically active materials for multimodality imaging. Acc. Chem. Res. 2009; 42:904-914. [PubMed: 19435319]

6. Mitragotri S, Lahann J. Physical approaches to biomaterial design. Nature Mater. 2009; 8:15-23. [PubMed: 19096389] This is a detailed review about the influence of biomaterial design on the in vivo behaviour of the biomaterials.

7. Zhang L, et al. Nanoparticles in medicine: therapeutic applications and developments. Clin. Pharmacol. Ther. 2008; 83:761-769. [PubMed: 17957183]

8. Farokhzad OC, Langer R. Impact of nanotechnology on drug delivery. ACS Nano. 2009; 3:16-20. [PubMed: 19206243]

9. Davis ME, Chen ZG, Shin DM. Nanoparticle therapeutics: an emerging treatment modality for cancer. Nature Rev. Drug Discov. 2008; 7:771-782. [PubMed: 18758474]

10. Allen TM. Long-circulating (sterically stabilized) liposomes for targeted drug delivery. Trends Pharmacol. Sci. 1994; 15:215-220. [PubMed: 7940982]

11. van Dalen EC, Michiels EM, Caron HN, Kremer LC. Different anthracycline derivates for reducing cardiotoxicity in cancer patients. Cochrane Database Syst. Rev. 2010:CD005006.

12. Terreno E, Castelli DD, Viale A, Aime S. Challenges for molecular magnetic resonance imaging. Chem. Rev. 2010; 110:3019-3042. [PubMed: 20415475]

13. Yu SB, Watson AD. Metal-based X-ray contrast media. Chem. Rev. 1999; 99:2353-2378. [PubMed: 11749484]

14. Chen K, Conti PS. Target-specific delivery of peptide-based probes for PET imaging. Adv. Drug Deliv. Rev. 2010; 62:1005-1022. [PubMed: 20851156]

15. Kobayashi H, Ogawa M, Alford R, Choyke PL, Urano Y. New strategies for fluorescent probe design in medical diagnostic imaging. Chem. Rev. 2010; 110:2620-2640. [PubMed: 20000749]

16. Allen TM, Cullis PR. Drug delivery systems: entering the mainstream. Science. 2004; 303:18181822. [PubMed: 15031496]

17. Ford ES, et al. Explaining the decrease in U.S. deaths from coronary disease, 1980-2000. N. Engl. J. Med. 2007; 356:2388-2398. [PubMed: 17554120]

18. Roger VL, et al. Heart disease and stroke statistics-2011 update: a report from the American Heart Association. Circulation. 2011; 123:e18-e209. [PubMed: 21160056]

19. Naghavi M, et al. From vulnerable plaque to vulnerable patient: a call for new definitions and risk assessment strategies: Part I. Circulation. 2003; 108:1664-1672. [PubMed: 14530185]

20. Falk E. Pathogenesis of atherosclerosis. J. Am. Coll. Cardiol. 2006; 47:C7-C12. [PubMed: 16631513] This is a comprehensive review on the pathogenesis of atherosclerosis.

21. Chiu JJ, Chien S. Effects of disturbed flow on vascular endothelium: pathophysiological basis and clinical perspectives. Physiol. Rev. 2011; 91:327-387. [PubMed: 21248169]

22. Tabas I, Williams KJ, Boren J. Subendothelial lipoprotein retention as the initiating process in atherosclerosis: update and therapeutic implications. Circulation. 2007; 116:1832-1844. [PubMed: 17938300]

23. Tabas I. Macrophage death and defective inflammation resolution in atherosclerosis. Nature Rev. Immunol. 2010; 10:36-46. [PubMed: 19960040]

24. Moreno PR, Purushothaman KR, Sirol M, Levy AP, Fuster V. Neovascularization in human atherosclerosis. Circulation. 2006; 113:2245-2252. [PubMed: 16684874]

25. Moreno PR, Sanz J, Fuster V. Promoting mechanisms of vascular health: circulating progenitor cells, angiogenesis, and reverse cholesterol transport. J. Am. Coll. Cardiol. 2009; 53:2315-2323. [PubMed: 19539140]

26. Kolodgie FD, et al. Elimination of neoangiogenesis for plaque stabilization: is there a role for local drug therapy? J. Am. Coll. Cardiol. 2007; 49:2093-2101. [PubMed: 17531658] 
27. Libby P. Inflammation in atherosclerosis. Nature. 2002; 420:868-874. [PubMed: 12490960]

28. Hansson GK, Libby P. The immune response in atherosclerosis: a double-edged sword. Nature Rev. Immunol. 2006; 6:508-519. [PubMed: 16778830]

29. Falk E, Shah PK, Fuster V. Coronary plaque disruption. Circulation. 1995; 92:657-671. [PubMed: 7634481]

30. Coussens LM, Werb Z. Inflammation and cancer. Nature. 2002; 420:860-867. [PubMed: 12490959]

31. Mantovani A, Allavena P, Sica A, Balkwill F. Cancer-related inflammation. Nature. 2008; 454:436-444. [PubMed: 18650914]

32. Ferrari M. Cancer nanotechnology: opportunities and challenges. Nature Rev. Cancer. 2005; 5:161-171. [PubMed: 15738981]

33. Peer D, et al. Nanocarriers as an emerging platform for cancer therapy. Nature Nanotechnol. 2007; 2:751-760. [PubMed: 18654426]

34. Matsumura Y, Maeda H. A new concept for macromolecular therapeutics in cancer chemotherapy: mechanism of tumoritropic accumulation of proteins and the antitumor agent smancs. Cancer Res. 1986; 46:6387-6392. [PubMed: 2946403]

35. Fang J, Nakamura H, Maeda H. The EPR effect: unique features of tumor blood vessels for drug delivery, factors involved, and limitations and augmentation of the effect. Adv. Drug Deliv. Rev. 2011; 63:136-151. [PubMed: 20441782]

36. Tarbell JM. Shear stress and the endothelial transport barrier. Cardiovasc. Res. 2010; 87:320-330. [PubMed: 20543206]

37. van Bochove GS, et al. Contrast enhancement by differently sized paramagnetic MRI contrast agents in mice with two phenotypes of atherosclerotic plaque. Contrast Media Mol. Imaging. 2011; 6:35-45. [PubMed: 20882509]

38. Flogel U, et al. In vivo monitoring of inflammation after cardiac and cerebral ischemia by fluorine magnetic resonance imaging. Circulation. 2008; 118:140-148. [PubMed: 18574049]

39. Torchilin VP. Multifunctional nanocarriers. Adv. Drug Deliv. Rev. 2006; 58:1532-1555. [PubMed: 17092599]

40. Hansson GK. Inflammation, atherosclerosis, and coronary artery disease. N. Engl. J. Med. 2005; 352:1685-1695. [PubMed: 15843671]

41. Jiang W, Kim BY, Rutka JT, Chan WC. Nanoparticle-mediated cellular response is sizedependent. Nature Nanotechnol. 2008; 3:145-150. [PubMed: 18654486]

42. O'Neil CP, et al. Extracellular matrix binding mixed micelles for drug delivery applications. J. Control Release. 2009; 137:146-151. [PubMed: 19332089]

43. Briley-Saebo KC, et al. Targeted iron oxide particles for in vivo magnetic resonance detection of atherosclerotic lesions with antibodies directed to oxidation-specific epitopes. J. Am. Coll. Cardiol. 2011; 57:337-347. [PubMed: 21106318]

44. Kirpotin DB, et al. Antibody targeting of longcirculating lipidic nanoparticles does not increase tumor localization but does increase internalization in animal models. Cancer Res. 2006; 66:67326740. [PubMed: 16818648] This study demonstrates that ligand-directed targeting can increase cell internalization.

45. Bartlett DW, Su H, Hildebrandt IJ, Weber WA, Davis ME. Impact of tumor-specific targeting on the biodistribution and efficacy of siRNA nanoparticles measured by multimodality in vivo imaging. Proc. Natl Acad. Sci. USA. 2007; 104:15549-15554. [PubMed: 17875985]

46. Lanza GM, et al. Angiogenesis imaging with vascular-constrained particles: the why and how. Eur. J. Nucl. Med. Mol. Imaging. 2010; 37(Suppl. 1):114-126. [PubMed: 19662408]

47. Nahrendorf $M$, et al. Noninvasive vascular cell adhesion molecule-1 imaging identifies inflammatory activation of cells in atherosclerosis. Circulation. 2006; 114:1504-1511. [PubMed: 17000904] This is an example of a multimodal nanoparticle being used to detect plaque inflammation via target-specific imaging of adhesion molecules.

48. Libby P. The forgotten majority: unfinished business in cardiovascular risk reduction. J. Am. Coll. Cardiol. 2005; 46:1225-1228. [PubMed: 16198835] 
49. Miller GJ, Miller NE. Plasma-high-density-lipoprotein concentration and development of ischaemic heart-disease. Lancet. 1975; 1:16-19. [PubMed: 46338]

50. Gordon DJ, Rifkind BM. High-density lipoprotein — the clinical implications of recent studies. N. Engl. J. Med. 1989; 321:1311-1316. [PubMed: 2677733]

51. Navab M, Reddy ST, Van Lenten BJ, Fogelman AM. HDL and cardiovascular disease: atherogenic and atheroprotective mechanisms. Nature Rev. Cardiol. 2011; 8:222-232. [PubMed: 21304474]

52. Khera AV, et al. Cholesterol efflux capacity, high-density lipoprotein function, and atherosclerosis. N. Engl. J. Med. 2011; 364:127-135. [PubMed: 21226578]

53. Briel M, et al. Association between change in high density lipoprotein cholesterol and cardiovascular disease morbidity and mortality: systematic review and meta-regression analysis. BMJ. 2009; 338:b92. [PubMed: 19221140]

54. Degoma EM, Rader DJ. Novel HDL-directed pharmacotherapeutic strategies. Nature Rev. Cardiol. 2011; 8:266-277. [PubMed: 21243009]

55. Badimon JJ, Badimon L, Galvez A, Dische R, Fuster V. High density lipoprotein plasma fractions inhibit aortic fatty streaks in cholesterol-fed rabbits. Lab. Invest. 1989; 60:455-461. [PubMed: 2927083]

56. Badimon JJ, Badimon L, Fuster V. Regression of atherosclerotic lesions by high density lipoprotein plasma fraction in the cholesterol-fed rabbit. J. Clin. Invest. 1990; 85:1234-1241. [PubMed: 2318976]

57. Shah PK, et al. Effects of recombinant apolipoprotein A-I Milano on aortic atherosclerosis in apolipoprotein E-deficient mice. Circulation. 1998; 97:780-785. [PubMed: 9498542]

58. Shah PK, et al. High-dose recombinant apolipoprotein A-I Milano mobilizes tissue cholesterol and rapidly reduces plaque lipid and macrophage content in apolipoprotein E-deficient mice. Potential implications for acute plaque stabilization. Circulation. 2001; 103:3047-3050. [PubMed: 11425766]

59. Chiesa G, et al. Recombinant apolipoprotein A-I Milano infusion into rabbit carotid artery rapidly removes lipid from fatty streaks. Circ. Res. 2002; 90:974-980. [PubMed: 12016263]

60. Ibanez B, et al. Rapid change in plaque size, composition, and molecular footprint after

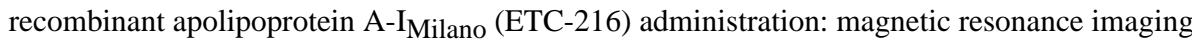
study in an experimental model of atherosclerosis. J. Am. Coll. Cardiol. 2008; 51:1104-1109. [PubMed: 18342230]

61. Kaul S, et al. Rapid reversal of endothelial dysfunction in hypercholesterolemic apolipoprotein Enull mice by recombinant apolipoprotein A-IMilano-phospholipid complex. J. Am. Coll. Cardiol. 2004; 44:1311-1319. [PubMed: 15364338]

62. Nissen SE, et al. Effect of recombinant ApoA-I Milano on coronary atherosclerosis in patients with acute coronary syndromes: a randomized controlled trial. JAMA. 2003; 290:2292-2300. [PubMed: 14600188] This article presents the results of a clinical trial with infusions of reconstituted HDL that demonstrated regression of coronary atherosclerosis as measured by intravascular ultrasound imaging.

63. Nicholls SJ, et al. Relationship between atheroma regression and change in lumen size after infusion of apolipoprotein A-I Milano. J. Am. Coll. Cardiol. 2006; 47:992-997. [PubMed: 16516083]

64. Bloedon LT, et al. Safety, pharmacokinetics, and pharmacodynamics of oral apoA-I mimetic peptide D-4F in high-risk cardiovascular patients. J. Lipid Res. 2008; 49:1344-1352. [PubMed: 18323573]

65. Navab M, et al. Structure and function of HDL mimetics. Arterioscler. Thromb. Vasc. Biol. 2010; 30:164-168. [PubMed: 19608977]

66. Vickers KC, Palmisano BT, Shoucri BM, Shamburek RD, Remaley AT. MicroRNAs are transported in plasma and delivered to recipient cells by high-density lipoproteins. Nature Cell Biol. 2011; 13:423-433. [PubMed: 21423178]

67. Rensen PC, et al. Recombinant lipoproteins: lipoprotein-like lipid particles for drug targeting. Adv. Drug Deliv. Rev. 2001; 47:251-276. [PubMed: 11311995]

68. Yang M, et al. Efficient cytosolic delivery of siRNA using HDL-mimicking nanoparticles. Small. 2011; 7:568-573. [PubMed: 21370456] 
69. McMahon KM, et al. Biomimetic high density lipoprotein nanoparticles for nucleic acid delivery. Nano Lett. 2011; 11:1208-1214. [PubMed: 21319839]

70. Skajaa T, et al. High-density lipoprotein-based contrast agents for multimodal imaging of atherosclerosis. Arterioscler. Thromb. Vasc. Biol. 2010; 30:169-176. [PubMed: 19815819]

71. Thaxton CS, Daniel WL, Giljohann DA, Thomas AD, Mirkin CA. Templated spherical high density lipoprotein nanoparticles. J. Am. Chem. Soc. 2009; 131:1384-1385. [PubMed: 19133723]

72. Skajaa T, et al. The biological properties of iron oxide core high-density lipoprotein in experimental atherosclerosis. Biomaterials. 2011; 32:206-213. [PubMed: 20926130]

73. Zheng G, Chen J, Li H, Glickson JD. Rerouting lipoprotein nanoparticles to selected alternate receptors for the targeted delivery of cancer diagnostic and therapeutic agents. Proc. Natl Acad. Sci. USA. 2005; 102:17757-17762. [PubMed: 16306263]

74. Cannon CP, Steinberg BA, Murphy SA, Mega JL, Braunwald E. Meta-analysis of cardiovascular outcomes trials comparing intensive versus moderate statin therapy. J. Am. Coll. Cardiol. 2006; 48:438-445. [PubMed: 16875966]

75. Armitage J, et al. Intensive lowering of LDL cholesterol with $80 \mathrm{mg}$ versus $20 \mathrm{mg}$ simvastatin daily in 12,064 survivors of myocardial infarction: a double-blind randomised trial. Lancet. 2010; 376:1658-1669. [PubMed: 21067805]

76. Zimmermann TS, et al. RNAi-mediated gene silencing in non-human primates. Nature. 2006; 441:111-114. [PubMed: 16565705] This study demonstrates the potential of systemic lipidlowering by liposome-encapsulated siRNA.

77. Semple SC, et al. Rational design of cationic lipids for siRNA delivery. Nature Biotech. 2010; 28:172-176.

78. Love KT, et al. Lipid-like materials for low-dose in vivo gene silencing. Proc. Natl Acad. Sci. USA. 2010; 107:1864-1869. [PubMed: 20080679]

79. Libby P, Ridker PM, Hansson GK. Inflammation in atherosclerosis: from pathophysiology to practice. J. Am. Coll. Cardiol. 2009; 54:2129-2138. [PubMed: 19942084]

80. Charo IF, Taub R. Anti-inflammatory therapeutics for the treatment of atherosclerosis. Nature Rev. Drug Discov. 2011; 10:365-376. [PubMed: 21532566]

81. Poon M, et al. Dexamethasone inhibits macrophage accumulation after balloon arterial injury in cholesterol fed rabbits. Atherosclerosis. 2001; 155:371-380. [PubMed: 11254907]

82. Lobatto ME, et al. Multimodal clinical imaging to longitudinally assess a nanomedical antiinflammatory treatment in experimental atherosclerosis. Mol. Pharm. 2010; 7:2020-2029. [PubMed: 21028895] This study shows the ability of non-invasive imaging to longitudinally monitor therapeutic response in a rabbit model of atherosclerosis after nanomedical treatment.

83. Mauriello A, et al. Diffuse and active inflammation occurs in both vulnerable and stable plaques of the entire coronary tree: a histopathologic study of patients dying of acute myocardial infarction. J. Am. Coll. Cardiol. 2005; 45:1585-1593. [PubMed: 15893171]

84. McCarthy JR, Korngold E, Weissleder R, Jaffer FA. A light-activated theranostic nanoagent for targeted macrophage ablation in inflammatory atherosclerosis. Small. 2010; 6:2041-2049. [PubMed: 20721949]

85. Dangas GD, et al. In-stent restenosis in the drug-eluting stent era. J. Am. Coll. Cardiol. 2010; 56:1897-1907. [PubMed: 21109112]

86. Pendyala LK, et al. The first-generation drug-eluting stents and coronary endothelial dysfunction. JACC Cardiovasc. Interv. 2009; 2:1169-1177. [PubMed: 20129542]

87. Luscher TF, et al. Drug-eluting stent and coronary thrombosis: biological mechanisms and clinical implications. Circulation. 2007; 115:1051-1058. [PubMed: 17325255]

88. Nakazawa G, et al. The pathology of neoatherosclerosis in human coronary implants: bare-metal and drug-eluting stents. J. Am. Coll. Cardiol. 2011; 57:1314-1322. [PubMed: 21376502]

89. Danenberg HD, et al. Macrophage depletion by clodronate-containing liposomes reduces neointimal formation after balloon injury in rats and rabbits. Circulation. 2002; 106:599-605. [PubMed: 12147543]

90. Danenberg HD, et al. Liposomal alendronate inhibits systemic innate immunity and reduces instent neointimal hyperplasia in rabbits. Circulation. 2003; 108:2798-2804. [PubMed: 14610008] 
91. Joner M, et al. Site-specific targeting of nanoparticle prednisolone reduces in-stent restenosis in a rabbit model of established atheroma. Arterioscler. Thromb. Vasc. Biol. 2008; 28:1960-1966. [PubMed: 18688017]

92. Ribichini F, et al. Immunosuppressive therapy with oral prednisone to prevent restenosis after PCI. A multicenter randomized trial. Am. J. Med. 2011; 124:434-443. [PubMed: 21531233]

93. Kolodgie FD, et al. Sustained reduction of in-stent neointimal growth with the use of a novel systemic nanoparticle paclitaxel. Circulation. 2002; 106:1195-1198. [PubMed: 12208792]

94. Uwatoku T, et al. Application of nanoparticle technology for the prevention of restenosis after balloon injury in rats. Circ. Res. 2003; 92:e62-e69. [PubMed: 12663484]

95. Abid MR, et al. Forkhead transcription factors inhibit vascular smooth muscle cell proliferation and neointimal hyperplasia. J. Biol. Chem. 2005; 280:29864-29873. [PubMed: 15961397]

96. Li JM, et al. Local arterial nanoparticle delivery of siRNA for NOX2 knockdown to prevent restenosis in an atherosclerotic rat model. Gene Ther. 2010; 17:1279-1287. [PubMed: 20485380]

97. Lanza GM, et al. Targeted antiproliferative drug delivery to vascular smooth muscle cells with a magnetic resonance imaging nanoparticle contrast agent: implications for rational therapy of restenosis. Circulation. 2002; 106:2842-2847. [PubMed: 12451012]

98. Cyrus $T$, et al. Intramural delivery of rapamycin with $a_{v} \beta_{3}$-targeted paramagnetic nanoparticles inhibits stenosis after balloon injury. Arterioscler. Thromb. Vasc. Biol. 2008; 28:820-826. [PubMed: 18292395]

99. Chan JM, et al. Spatiotemporal controlled delivery of nanoparticles to injured vasculature. Proc. Natl Acad. Sci. USA. 2010; 107:2213-2218. [PubMed: 20133865]

100. Kaul S, et al. Intramural delivery of recombinant apolipoprotein A-I Milano/phospholipid complex (ETC-216) inhibits in-stent stenosis in porcine coronary arteries. Circulation. 2003; 107:25512554. [PubMed: 12742990]

101. Nakano K, et al. Formulation of nanoparticle-eluting stents by a cationic electrodeposition coating technology: efficient nano-drug delivery via bioabsorbable polymeric nanoparticle-eluting stents in porcine coronary arteries. JACC Cardiovasc. Interv. 2009; 2:277-283. [PubMed: 19463437]

102. Polyak B, et al. High field gradient targeting of magnetic nanoparticle-loaded endothelial cells to the surfaces of steel stents. Proc. Natl Acad. Sci. USA. 2008; 105:698-703. [PubMed: 18182491]

103. Chorny M, et al. Targeting stents with local delivery of paclitaxel-loaded magnetic nanoparticles using uniform fields. Proc. Natl Acad. Sci. USA. 2010; 107:8346-8351. [PubMed: 20404175]

104. Jain RK, Finn AV, Kolodgie FD, Gold HK, Virmani R. Antiangiogenic therapy for normalization of atherosclerotic plaque vasculature: a potential strategy for plaque stabilization. Nature Clin. Pract. Cardiovasc. Med. 2007; 4:491-502. [PubMed: 17712362]

105. Moulton KS, et al. Angiogenesis inhibitors endostatin or TNP-470 reduce intimal neovascularization and plaque growth in apolipoprotein E-deficient mice. Circulation. 1999; 99:1726-1732. [PubMed: 10190883]

106. Moulton KS, et al. Inhibition of plaque neovascularization reduces macrophage accumulation and progression of advanced atherosclerosis. Proc. Natl Acad. Sci. USA. 2003; 100:4736-4741. [PubMed: 12682294]

107. Winter PM, et al. Endothelial $a_{v} \beta_{3}$ integrin-targeted fumagillin nanoparticles inhibit angiogenesis in atherosclerosis. Arterioscler. Thromb. Vasc. Biol. 2006; 26:2103-2109. [PubMed: 16825592] This was the first study to show the therapeutic potential of combined molecular imaging and drug delivery with targeted nanoparticles in a rabbit model of atherosclerosis.

108. Winter PM, et al. Antiangiogenic synergism of integrin-targeted fumagillin nanoparticles and atorvastatin in atherosclerosis. JACC Cardiovasc. Imaging. 2008; 1:624-634. [PubMed: 19356492]

109. Hedman M, et al. Safety and feasibility of catheter-based local intracoronary vascular endothelial growth factor gene transfer in the prevention of postangioplasty and in-stent restenosis and in the treatment of chronic myocardial ischemia: Phase II results of the Kuopio Angiogenesis Trial (KAT). Circulation. 2003; 107:2677-2683. [PubMed: 12742981] 
110. Yla-Herttuala S, Rissanen TT, Vajanto I, Hartikainen J. Vascular endothelial growth factors: biology and current status of clinical applications in cardiovascular medicine. J. Am. Coll. Cardiol. 2007; 49:1015-1026. [PubMed: 17349880]

111. Kim J, Cao L, Shvartsman D, Silva EA, Mooney DJ. Targeted delivery of nanoparticles to ischemic muscle for imaging and therapeutic angiogenesis. Nano Lett. 2011; 11:694-700. [PubMed: 21192718]

112. Celletti FL, et al. Vascular endothelial growth factor enhances atherosclerotic plaque progression. Nature Med. 2001; 7:425-429. [PubMed: 11283668]

113. Peters D, et al. Targeting atherosclerosis by using modular, multifunctional micelles. Proc. Natl Acad. Sci. USA. 2009; 106:9815-9819. [PubMed: 19487682]

114. Myerson J, He L, Lanza G, Tollefsen D, Wickline S. Thrombin-inhibiting perfluorocarbon nanoparticles provide a novel strategy for the treatment and magnetic resonance imaging of acute thrombosis. J. Thromb. Haemost. 2011; 9:1292-1300. [PubMed: 21605330]

115. Uesugi Y, Kawata H, Jo J, Saito Y, Tabata Y. An ultrasound-responsive nano delivery system of tissue-type plasminogen activator for thrombolytic therapy. J. Control Release. 2010; 147:269277. [PubMed: 20696194]

116. Sanz J, Fayad ZA. Imaging of atherosclerotic cardiovascular disease. Nature. 2008; 451:953-957. [PubMed: 18288186] This is a review on the different methods of imaging atherosclerotic cardiovascular disease.

117. Weissleder R, Mahmood U. Molecular imaging. Radiology. 2001; 219:316-333. [PubMed: 11323453]

118. Chen IY, Wu JC. Cardiovascular molecular imaging: focus on clinical translation. Circulation. 2011; 123:425-443. [PubMed: 21282520]

119. Leuschner F, Nahrendorf M. Molecular imaging of coronary atherosclerosis and myocardial infarction: considerations for the bench and perspectives for the clinic. Circ. Res. 2011; 108:593606. [PubMed: 21372291] This is a review on the processes that can be targeted to enable the detection of coronary atherosclerosis by molecular imaging.

120. Buono C, Anzinger JJ, Amar M, Kruth HS. Fluorescent pegylated nanoparticles demonstrate fluid-phase pinocytosis by macrophages in mouse atherosclerotic lesions. J. Clin. Invest. 2009; 119:1373-1381. [PubMed: 19363293]

121. Louie A. Multimodality imaging probes: design and challenges. Chem. Rev. 2010; 110:31463195. [PubMed: 20225900] This is an extensive review on the synthesis and design of multimodal imaging probes.

122. Mulder WJ, et al. Magnetic and fluorescent nanoparticles for multimodality imaging. Nanomedicine (Lond.). 2007; 2:307-324. [PubMed: 17716176]

123. Underhill HR, Hatsukami TS, Fayad ZA, Fuster V, Yuan C. MRI of carotid atherosclerosis: clinical implications and future directions. Nature Rev. Cardiol. 2010; 7:165-173. [PubMed: 20101259]

124. Voros S, et al. Coronary atherosclerosis imaging by Coronary CT angiography: current status, correlation with intravascular interrogation and meta-analysis. JACC Cardiovasc. Imaging. 2011; 4:537-548. [PubMed: 21565743]

125. Sirol M, et al. Lipid-rich atherosclerotic plaques detected by gadofluorine-enhanced in vivo magnetic resonance imaging. Circulation. 2004; 109:2890-2896. [PubMed: 15184290]

126. Ruehm SG, Corot C, Vogt P, Kolb S, Debatin JF. Magnetic resonance imaging of atherosclerotic plaque with ultrasmall superparamagnetic particles of iron oxide in hyperlipidemic rabbits. Circulation. 2001; 103:415-422. [PubMed: 11157694] This was the first study to use USPIOenhanced MRI of atherosclerotic plaques in a rabbit model.

127. Woollard KJ, Geissmann F. Monocytes in atherosclerosis: subsets and functions. Nature Rev. Cardiol. 2010; 7:77-86. [PubMed: 20065951]

128. Kooi ME, et al. Accumulation of ultrasmall superparamagnetic particles of iron oxide in human atherosclerotic plaques can be detected by in vivo magnetic resonance imaging. Circulation. 2003; 107:2453-2458. [PubMed: 12719280]

129. Tang TY, et al. The ATHEROMA (Atorvastatin Therapy: Effects on Reduction of Macrophage Activity) Study. Evaluation using ultrasmall superparamagnetic iron oxide-enhanced magnetic 
resonance imaging in carotid disease. J. Am. Coll. Cardiol. 2009; 53:2039-2050. [PubMed: 19477353]

130. Fayad ZA, Razzouk L, Briley-Saebo KC, Mani V. Iron oxide magnetic resonance imaging for atherosclerosis therapeutic evaluation: still “rusty?". J. Am. Coll. Cardiol. 2009; 53:2051-2052. [PubMed: 19477354]

131. Corti R, et al. Effects of aggressive versus conventional lipid-lowering therapy by simvastatin on human atherosclerotic lesions: a prospective, randomized, double-blind trial with high-resolution magnetic resonance imaging. J. Am. Coll. Cardiol. 2005; 46:106-112. [PubMed: 15992643]

132. Flacke $S$, et al. Novel MRI contrast agent for molecular imaging of fibrin: implications for detecting vulnerable plaques. Circulation. 2001; 104:1280-1285. [PubMed: 11551880]

133. Winter PM, et al. Molecular imaging of angiogenesis in early-stage atherosclerosis with $a_{\mathrm{v}} \beta_{3^{-}}$ integrin-targeted nanoparticles. Circulation. 2003; 108:2270-2274. [PubMed: 14557370]

134. Amirbekian V, et al. Detecting and assessing macrophages in vivo to evaluate atherosclerosis noninvasively using molecular MRI. Proc. Natl Acad. Sci. USA. 2007; 104:961-966. [PubMed: 17215360]

135. van Tilborg GA, et al. Annexin A5-functionalized bimodal nanoparticles for MRI and fluorescence imaging of atherosclerotic plaques. Bioconjug. Chem. 2010; 21:1794-1803. [PubMed: 20804153]

136. Cormode DP, et al. Comparison of synthetic high density lipoprotein (HDL) contrast agents for MR imaging of atherosclerosis. Bioconjug. Chem. 2009; 20:937-943. [PubMed: 19378935]

137. Cormode DP, et al. Nanocrystal core high-density lipoproteins: a multimodality contrast agent platform. Nano Lett. 2008; 8:3715-3723. [PubMed: 18939808] This paper reports the effect of including nanocrystals in the core of HDL to enable its detection by multiple imaging techniques without compromising the important biophysical features of HDL.

138. Skajaa T, et al. Quantum dot and Cy5.5 labeled nanoparticles to investigate lipoprotein biointeractions via Förster resonance energy transfer. Nano Lett. 2010; 10:5131-5138.

139. Torchilin VP, Frank-Kamenetsky MD, Wolf GL. CT visualization of blood pool in rats by using long-circulating, iodine-containing micelles. Acad. Radiol. 1999; 6:61-65. [PubMed: 9891154]

140. Rabin O, Manuel Perez J, Grimm J, Wojtkiewicz G, Weissleder R. An X-ray computed tomography imaging agent based on long-circulating bismuth sulphide nanoparticles. Nature Mater. 2006; 5:118-122. [PubMed: 16444262]

141. Hyafil F, et al. Noninvasive detection of macrophages using a nanoparticulate contrast agent for computed tomography. Nature Med. 2007; 13:636-641. [PubMed: 17417649]

142. Cormode DP, et al. Atherosclerotic plaque composition: analysis with multicolor CT and targeted gold nanoparticles. Radiology. 2010; 256:774-782. [PubMed: 20668118]

143. Pan D, et al. Computed tomography in color: NanoK-enhanced spectral CT molecular imaging. Angew. Chem. Int. Ed. Engl. 2010; 49:9635-9639. [PubMed: 21077082]

144. Rudd JH, et al. Imaging atherosclerotic plaque inflammation by fluorodeoxyglucose with positron emission tomography: ready for prime time? J. Am. Coll. Cardiol. 2010; 55:2527-2535. [PubMed: 20513592]

145. Fujimoto $\mathrm{S}$, et al. Molecular imaging of matrix metalloproteinase in atherosclerotic lesions: resolution with dietary modification and statin therapy. J. Am. Coll. Cardiol. 2008; 52:18471857. [PubMed: 19038682]

146. Rominger A, et al. In vivo imaging of macrophage activity in the coronary arteries using $68 \mathrm{Ga}-$ DOTATATE PET/CT: correlation with coronary calcium burden and risk factors. J. Nucl. Med. 2010; 51:193-197. [PubMed: 20080898]

147. Kietselaer BL, et al. Noninvasive detection of plaque instability with use of radiolabeled annexin A5 in patients with carotid-artery atherosclerosis. N. Engl. J. Med. 2004; 350:1472-1473. [PubMed: 15070807]

148. Nahrendorf M, et al. Nanoparticle PET-CT imaging of macrophages in inflammatory atherosclerosis. Circulation. 2008; 117:379-387. [PubMed: 18158358] This study reports the effects of exploiting the favourable targeting properties of dextran-coated iron oxide nanoparticles for plaque imaging by PET-CT. 
149. Tassa C, Shaw SY, Weissleder R. Dextran-coated iron oxide nanoparticles: a versatile platform for targeted molecular imaging, molecular diagnostics, and therapy. Acc. Chem. Res. 2011 Jun 10 .

150. Almutairi A, et al. Biodegradable dendritic positron-emitting nanoprobes for the noninvasive imaging of angiogenesis. Proc. Natl Acad. Sci. USA. 2009; 106:685-690. [PubMed: 19129498]

151. Nahrendorf M, et al. Hybrid in vivo FMT-CT imaging of protease activity in atherosclerosis with customized nanosensors. Arterioscler. Thromb. Vasc. Biol. 2009; 29:1444-1451. [PubMed: 19608968]

152. Jaffer FA, Libby P, Weissleder R. Optical and multimodality molecular imaging: insights into atherosclerosis. Arterioscler. Thromb. Vasc. Biol. 2009; 29:1017-1024. [PubMed: 19359659]

153. Wang B, et al. Plasmonic intravascular photoacoustic imaging for detection of macrophages in atherosclerotic plaques. Nano Lett. 2009; 9:2212-2217. [PubMed: 18844426]

154. Lanza GM, et al. A novel site-targeted ultrasonic contrast agent with broad biomedical application. Circulation. 1996; 94:3334-3340. [PubMed: 8989148]

155. Lindner JR. Molecular imaging of cardiovascular disease with contrast-enhanced ultrasonography. Nature Rev. Cardiol. 2009; 6:475-481. [PubMed: 19506587]

156. Rader DJ, Daugherty A. Translating molecular discoveries into new therapies for atherosclerosis. Nature. 2008; 451:904-913. [PubMed: 18288179]

157. Dobrovolskaia MA, McNeil SE. Immunological properties of engineered nanomaterials. Nature Nanotechnol. 2007; 2:469-478. [PubMed: 18654343] This review describes the immunotoxicological aspects of nanotechnology-based therapeutic or diagnostic nanoparticles.

158. Choi HS, Frangioni JV. Nanoparticles for biomedical imaging: fundamentals of clinical translation. Mol. Imaging. 2010; 9:291-310. [PubMed: 21084027]

159. Bentzon JF, Falk E. Atherosclerotic lesions in mouse and man: is it the same disease? Curr. Opin. Lipidol. 2010; 21:434-440. [PubMed: 20683327]

160. Fitzgerald KT, et al. Standardization of models and methods used to assess nanoparticles in cardiovascular applications. Small. 2011; 7:705-717. [PubMed: 21319299]

161. Buxton DB, et al. Report of the national heart, lung, and blood institute working group on the translation of cardiovascular molecular imaging. Circulation. 2011; 123:2157-2163. [PubMed: 21576680]

162. Libby P, Ridker PM, Hansson GK. Progress and challenges in translating the biology of atherosclerosis. Nature. 2011; 473:317-325. [PubMed: 21593864] This review discusses targets for the treatment of atherosclerosis.

163. Lindsay AC, Choudhury RP. Form to function: current and future roles for atherosclerosis imaging in drug development. Nature Rev. Drug Discov. 2008; 7:517-529. [PubMed: 18483481] This review describes the role of atherosclerosis imaging on drug development.

164. Muntendam P, McCall C, Sanz J, Falk E, Fuster V. The BioImage Study: novel approaches to risk assessment in the primary prevention of atherosclerotic cardiovascular disease — study design and objectives. Am. Heart J. 2010; 160:49 e1-57 e1. [PubMed: 20598972]

165. Martinez AW, Chaikof EL. Microfabrication and nanotechnology in stent design. Wiley Interdiscip. Rev. Nanomed. Nanobiotechnol. 2011; 3:256-268. [PubMed: 21462356]

166. Dvir T, Timko BP, Kohane DS, Langer R. Nanotechnological strategies for engineering complex tissues. Nature Nanotechnol. 2011; 6:13-22. [PubMed: 21151110]

167. Park JS, et al. A highly sensitive and selective diagnostic assay based on virus nanoparticles. Nature Nanotechnol. 2009; 4:259-264. [PubMed: 19350038]

168. Takahama $\mathrm{H}$, et al. Prolonged targeting of ischemic/reperfused myocardium by liposomal adenosine augments cardioprotection in rats. J. Am. Coll. Cardiol. 2009; 53:709-717. [PubMed: 19232905]

169. Nahrendorf M, et al. Detection of macrophages in aortic aneurysms by nanoparticle positron emission tomography-computed tomography. Arterioscler. Thromb. Vasc. Biol. 2011; 31:750 757. [PubMed: 21252070]

170. Lanza GM, et al. Rationale for a nanomedicine approach to thrombolytic therapy. Stroke. 2010; 41:S42-S44. [PubMed: 20876503] 
171. Yu L, et al. Autonomic denervation with magnetic nanoparticles. Circulation. 2010; 122:26532659. [PubMed: 21135360]

172. Choi HS, et al. Renal clearance of quantum dots. Nature Biotech. 2007; 25:1165-1170. This is an excellent example of the influence of the size of a nanoparticle on its biodistribution and clearance.

173. Alexis F, Pridgen E, Molnar LK, Farokhzad OC. Factors affecting the clearance and biodistribution of polymeric nanoparticles. Mol. Pharm. 2008; 5:505-515. [PubMed: 18672949]

174. Klibanov AL, Maruyama K, Torchilin VP, Huang L. Amphipathic polyethyleneglycols effectively prolong the circulation time of liposomes. FEBS Lett. 1990; 268:235-237. [PubMed: 2384160]

175. Owens DE, Peppas NA. Opsonization, biodistribution, and pharmacokinetics of polymeric nanoparticles. Int. J. Pharm. 2006; 307:93-102. [PubMed: 16303268]

176. Knop K, Hoogenboom R, Fischer D, Schubert US. Poly(ethylene glycol) in drug delivery: pros and cons as well as potential alternatives. Angew. Chem. Int. Ed. Engl. 2010; 49:6288-6308. [PubMed: 20648499]

177. Petros RA, DeSimone JM. Strategies in the design of nanoparticles for therapeutic applications. Nature Rev. Drug Discov. 2010; 9:615-627. [PubMed: 20616808] This is a review on recent advances in the design and therapeutic potential of nanoparticles.

178. Nel AE, et al. Understanding biophysicochemical interactions at the nano-bio interface. Nature Mater. 2009; 8:543-557. [PubMed: 19525947]

179. Torchilin VP. Recent advances with liposomes as pharmaceutical carriers. Nature Rev. Drug Discov. 2005; 4:145-160. [PubMed: 15688077]

180. Williams KJ, Phillips MC, Rodrigueza WV. Structural and metabolic consequences of liposomelipoprotein interactions. Adv. Drug Deliv. Rev. 1998; 32:31-43. [PubMed: 10837634]

181. Williams KJ, Scalia R, Mazany KD, Rodrigueza WV, Lefer AM. Rapid restoration of normal endothelial functions in genetically hyperlipidemic mice by a synthetic mediator of reverse lipid transport. Arterioscler. Thromb. Vasc. Biol. 2000; 20:1033-1039. [PubMed: 10764669]

182. Rodrigueza WV, Klimuk SK, Pritchard PH, Hope MJ. Cholesterol mobilization and regression of atheroma in cholesterol-fed rabbits induced by large unilamellar vesicles. Biochim. Biophys. Acta. 1998; 1368:306-320. [PubMed: 9459607]

183. Caride VJ, Zaret BL. Liposome accumulation in regions of experimental myocardial infarction. Science. 1977; 198:735-738. [PubMed: 910155]

184. Hodis HN, et al. Relationship of arterial wall uptake of radiolabeled liposomes to the presence of monocyte/macrophage cells in the hypertensive and atherosclerotic arterial wall. Atherosclerosis. 1991; 87:109-117. [PubMed: 1854358]

185. Torchilin VP, et al. Targeted accumulation of polyethylene glycol-coated immunoliposomes in infarcted rabbit myocardium. FASEB J. 1992; 6:2716-2719. [PubMed: 1612296] 


\section{Box 1 | Nanoparticle pharmacokinetics}

To enable efficient targeting of specific processes, several factors should be taken into account - most of them related to pharmacokinetics and/or biodistribution. Upon their intravenous administration, nanoparticles can be distributed over organs and tissues, followed by rapid renal clearance when the hydrodynamic diameter is less than $5.5 \mathrm{~nm}$, as shown in rodent models ${ }^{172}$. Most nanoparticle agents have a hydrodynamic diameter that is considerably larger, causing them to be cleared from the bloodstream predominantly by the mononuclear phagocyte system of the liver and spleen. The initial removal of the nanoparticles occurs through their binding to opsonin proteins in the circulation and their subsequent uptake by the mononuclear phagocyte system, which can be useful for targeting the liver but represents a substantial obstacle for efficient targeting of atherosclerotic plaques ${ }^{173}$. To ensure efficient targeting of plaques, rapid removal of nanoparticles by the mononuclear phagocyte system should be prevented to prolong their circulation time in the blood, enabling nanoparticles to reach and accumulate in tissues and exert their effects. Specific size, surface charge and stability can all contribute to enhanced circulatory half-life ${ }^{6}$. One of the most commonly used methods to evade rapid clearance via the mononuclear phagocyte system is the addition of hydrophilic polymers such as polyethylene glycol (PEG) to the surface of the nanoparticle ${ }^{174,175}$. In addition to PEG, various alternative polymers - some of which are biodegradable - are under investigation for the same purpose ${ }^{176}$. Detailed discussions of how nanoparticle design affects pharmacokinetics have previously been published (reviewed in REFS 177,178). 


\section{Box 2 | Use of liposomes for atherosclerosis therapy}

Liposomes, which are artificially prepared spherical self-closed structures formed by lipid bilayers that have an aqueous interior ${ }^{179}$, have also displayed anti-atherogenic properties. These are based on the ability of an initially cholesterol-free phospholipid bilayer to pick up cholesterol from lipoproteins or the atherosclerotic vessel wall ${ }^{180}$. Intravenous bolus injections of liposomes rapidly restored endothelial function, decreased leukocyte adhesion and reduced aortic cholesterol content and lesion thickness in animal models $^{181,182}$.

Liposomes have several attractive properties, as they are biocompatible and can entrap hydrophilic or hydrophobic pharmaceutical agents. They can be easily modified and have the ability to deliver pharmaceutical agents into cells ${ }^{179}$. Since their discovery in the 1960s, they have been extensively researched as drug carriers. They have also been shown to accumulate in experimental infarcted myocardium ${ }^{183}$ and the hypertensive and atherosclerotic arterial wall ${ }^{184}$, and their accumulation can be increased by conjugation to polyethylene glycol ${ }^{185}$. Liposomes are currently being investigated for several therapeutic strategies such as lipid-lowering, anti-inflammatory and antirestenotic therapy. 


\section{Box 3 | How imaging can facilitate nanomedical applications for atherosclerosis}

The development of novel nanomedical strategies for atherosclerosis can be facilitated by medical imaging at various levels and within different frameworks. Novel nanomaterials need to be thoroughly characterized with respect to their biodistribution within the body following their intravenous administration, preferably in vivo and in a longitudinal fashion. Labelling of nanoparticles with a radionucleotide provides a unique tool for quantitatively visualizing the biodistribution of the nanoparticle over time via nuclear imaging, most notably via positron emission tomography (PET). Different constituents - such as the carrier material itself or the payload - of the nanoparticle can be labelled, which allows for a focused determination of the ultimate fate of the formulation. In the setting of atherosclerosis, the systemic nature of the condition further supports the approach mentioned above, and also facilitates the use of imaging as an end point for nanotherapeutics. In this context, both anatomical and functional imaging strategies, including dynamic contrast-enhanced magnetic resonance imaging (DCE-MRI) and PET, are becoming increasingly valuable. Additionally, nanoparticle-facilitated molecular imaging is an important category within nanomedicine. The capability to include high payloads of contrast-generating materials makes nanoparticles attractive as probes for molecular imaging by MRI or computed tomography imaging in atherosclerosis, whereas their affinity for atherosclerotic lesions and the favourable biodistribution of certain nanomaterials makes them well suited to serve as PET tracers. 


\section{Box 4 | Clinical indications for nanomedicine-based therapy and diagnosis}

The intravenous injection of nanoparticulate agents can be envisioned for the following future clinical scenarios:

- Systemic rapid plaque regression after an acute coronary syndrome or other atherothrombotic events, for the prevention of future events

- Lipid-lowering in high-risk patients who are unresponsive to conventional lipidlowering techniques such as oral statin therapy or a change in diet, or for rapid lipid-lowering after a clinical event

- Anti-inflammatory or anti-angiogenic treatment after an acute coronary syndrome or in peripheral artery disease

- Adjunct therapy for the prevention of in-stent restenosis in patients after balloon angioplasty or in patients receiving bare-metal stents

- Pro-angiogenic treatment of patients with critical limb ischaemia in peripheral artery disease, or after a myocardial infarction or stroke

- Early diagnosis of atherosclerotic lesions that are prone to rupture

- Follow-up of inflammatory status or lesion thickness after treatment for a clinical event 


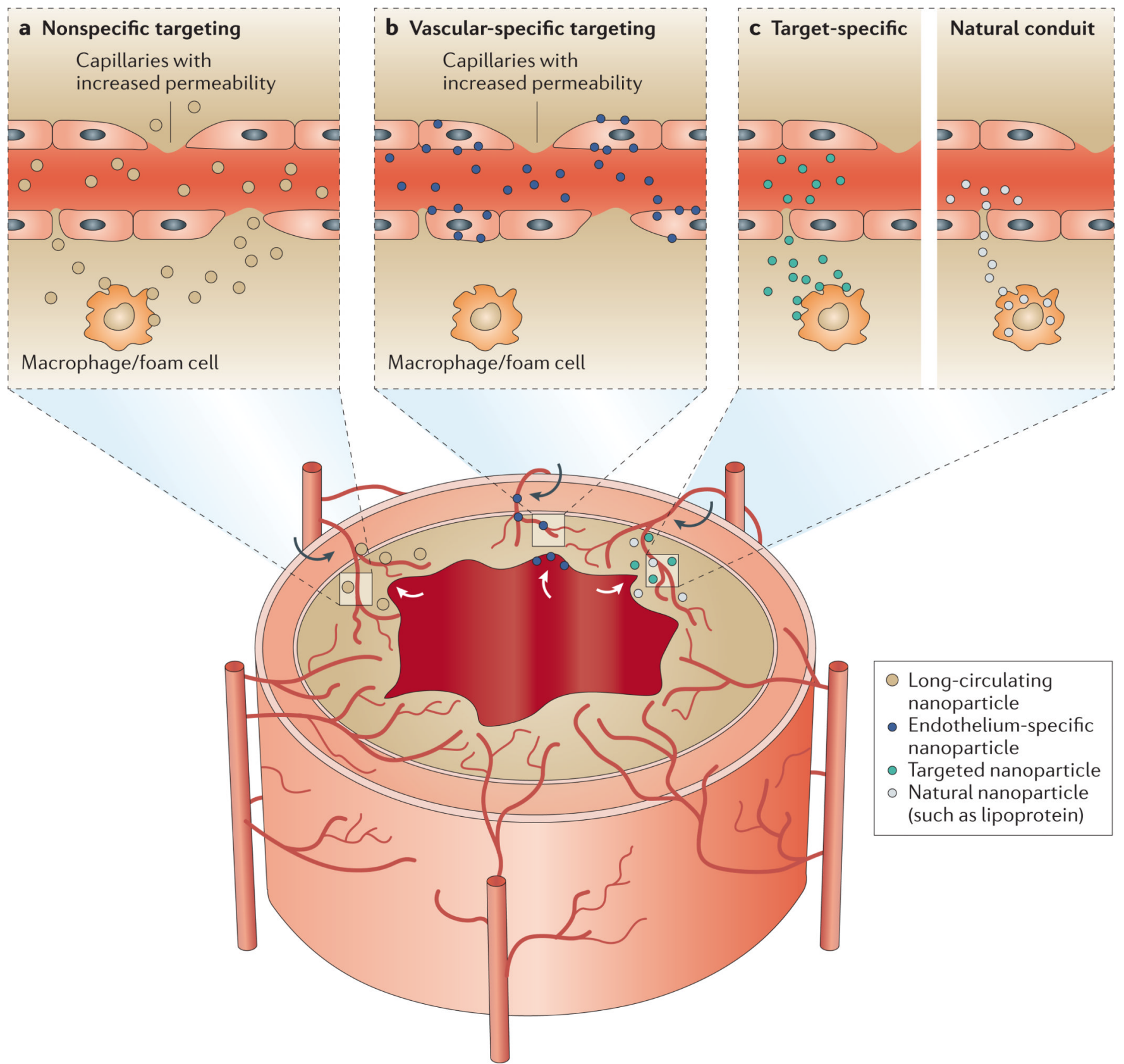

Figure 1. Targeting principles in atherosclerotic plaques

The vessel walls of larger arteries are supplied with nutrients by the lumen and the vasa vasorum - a network of small microvessels. In the lesioned vessel wall the vasa vasorum undergoes angiogenic expansion, with neovessels reaching into the base of the plaque, which is accompanied by the upregulation of cell-surface receptors and increased permeability of the endothelium. The upregulation of receptors and the increased permeability also affect the endothelium on the luminal side of the plaque. The main targeting principles can be classified into nonspecific targeting of the plaque (part a), specific targeting of the vasculature (part b) and specific targeting of components (part $\mathbf{c}$ ) of the plaque (for example, the extracellular matrix or macrophages) with either synthetic nanoparticles or via interaction through a natural conduit. The targeting of the plaque occurs 
via both the vasa vasorum and the main lumen at lesioned sites, and is exemplified on the figure with corresponding arrows. Depending on the targeting principle applied, the cellular distribution of nanoparticles in the plaque will vary considerably. 

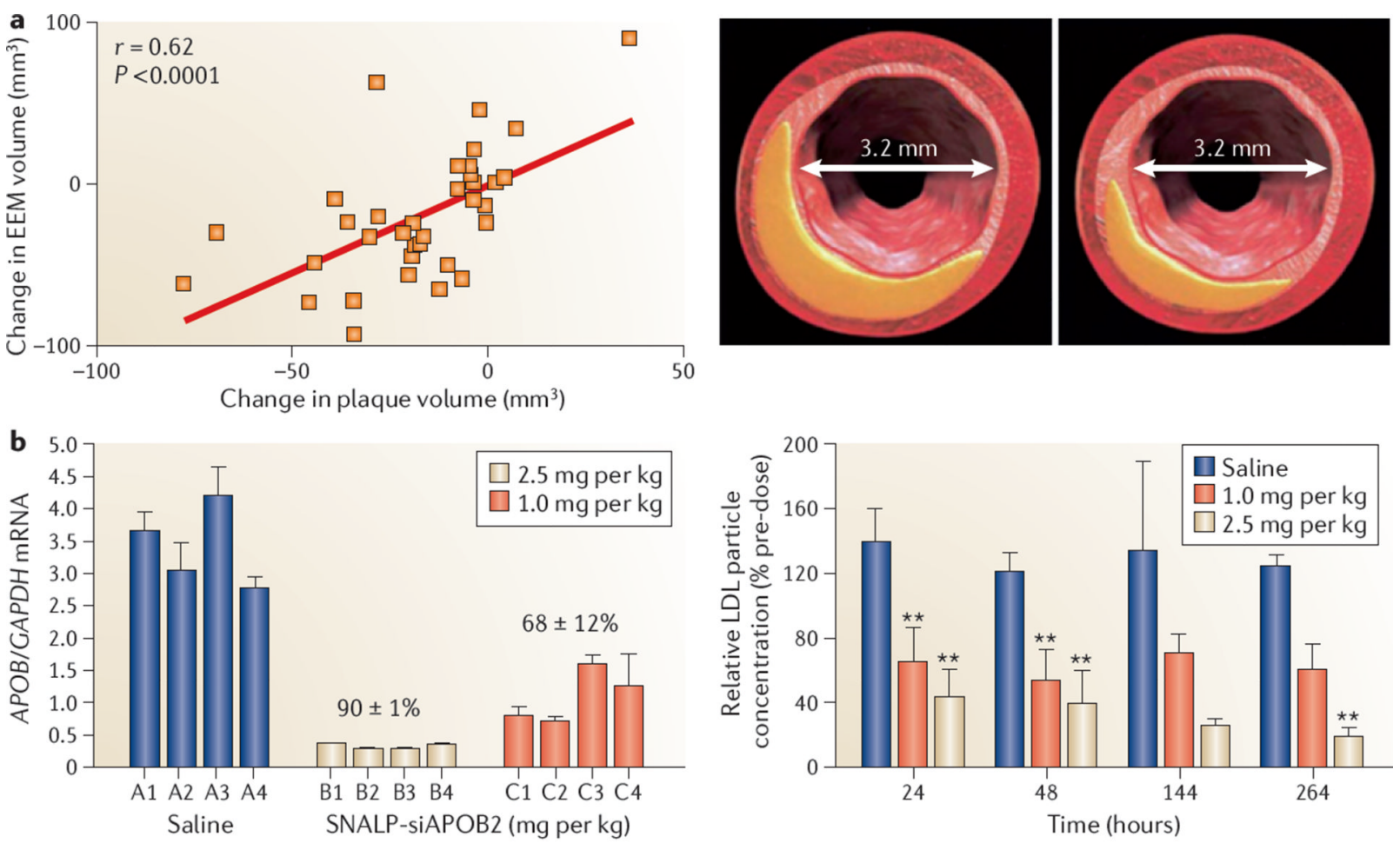

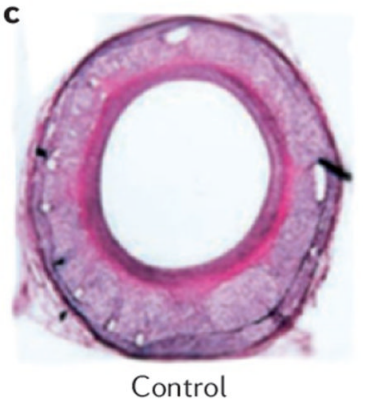

d

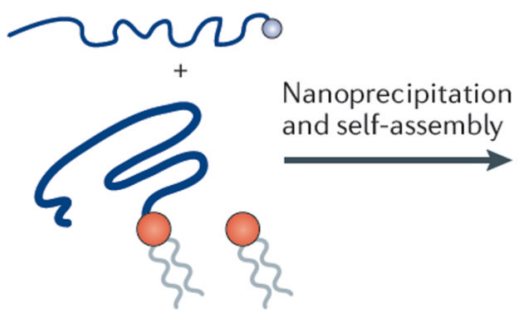

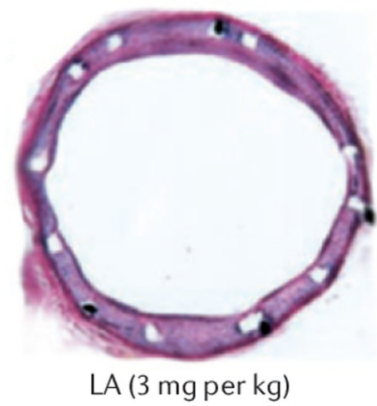

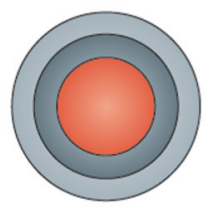

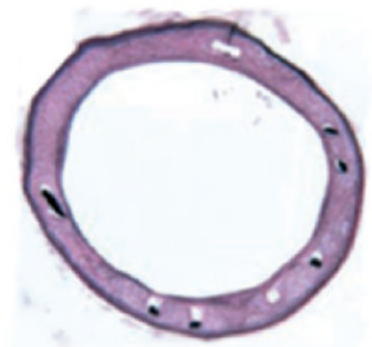

LA (6 mg per $\mathrm{kg}$ )

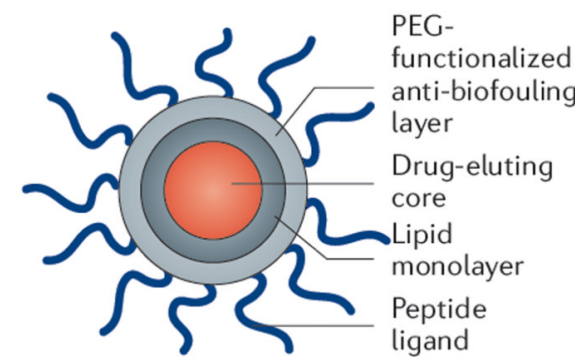

Figure 2. Applications of nanomedicine in the treatment of atherosclerotic disease a Administration of high-density lipoprotein to patients 2 weeks after an acute coronary syndrome leads to coronary plaque regression, shown with representative cross-sectional intravascular ultrasound images of matched arterial segments at baseline (left) and follow-up (right). The graph represents the correlation between the change in external elastic membrane (EEM) volume and the change in plaque volume. There was a concomitant reduction in the EEM volume but no change in the lumen size after 2 weeks. b| The effect of systemic silencing of apolipoprotein $\mathrm{B}(A P O B)$ mRNA in non-human primates is shown. The graph on the left shows apolipoprotein $\mathrm{B}(A P O B)$ mRNA levels quantified relative to 
glyceraldehydes-3-phosphate dehydrogenase $(G A P D H)$ mRNA in biopsy samples from the liver of four non-human primates per group, which are individually numbered (A1-C4), 2 days after treatment with stable nucleic acid lipid particles (SNALPs) encapsulating $A P O B-$ specific small interfering RNA (siAPOB2). Data are mean values for each animal. The percentage values above the groups reflect the mean values of the percentage reduction in $A P O B$ mRNA compared to saline treatment. The graph on the right shows serial plasma samples of low-density lipoprotein (LDL) obtained from non-human primates treated with saline or liposome-encapsulated small interfering RNA. Asterisks indicate clinical significance compared with the saline-treated group. c $\mid$ In-stent restenosis is reduced in rabbit iliac artery stents after liposomal alendronate (LA) injection, which is administered concurrently with stent implantation. $\mathbf{d} \mid$ A schematic is shown, illustrating the self-assembly of lipids and a drug-conjugated polymer (left), which results in a hybrid nanoparticle with a slow drug-eluting polymer core and a lipid corona (middle), which is subsequently functionalized with peptide ligands (right). This nanoparticle platform can potentially be used to target injured vasculature for the prevention of in-stent restenosis. PEG, polyethylene glycol. Panel a is modified, with permission, from REF. 63 @ (2006) American College of Cardiology. Panel b is modified, with permission, from REF. 76 () (2006) Macmillan Publishers Ltd. All rights reserved. Panel $\mathbf{c}$ is modified, with permission, from REF. 90 @ (2003) American Heart Association. Panel d is modified, with permission, from REF. 99 () (2010) National Academy of Sciences, USA. 


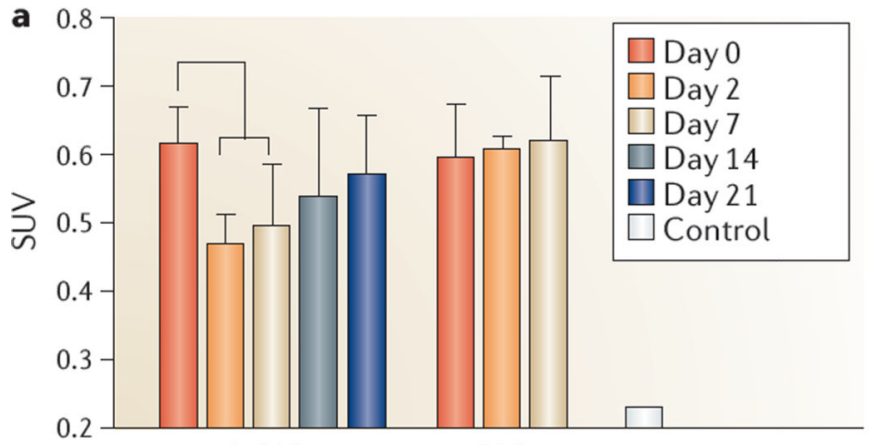
L-PLP PLP
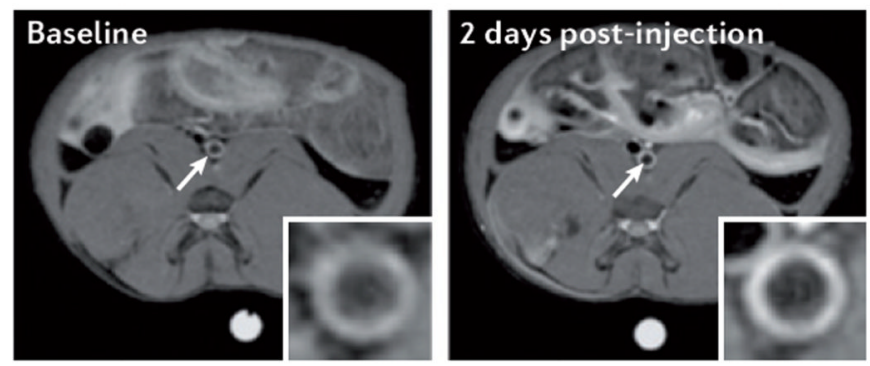

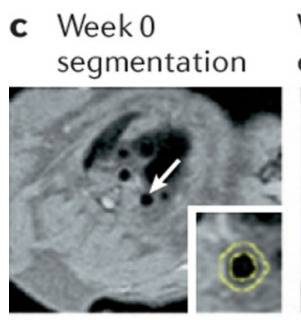

Week 2 enhancement

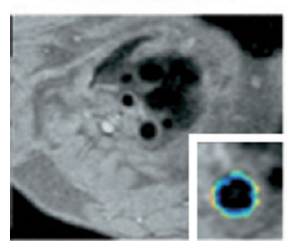

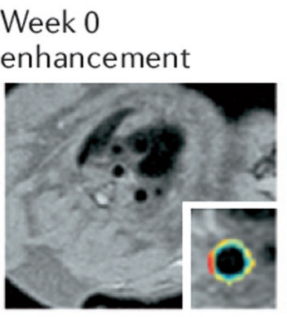

Week 3 enhancement

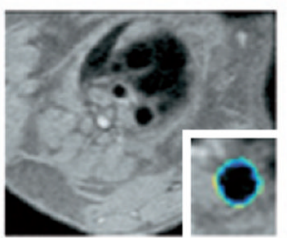

Week 1

enhancement

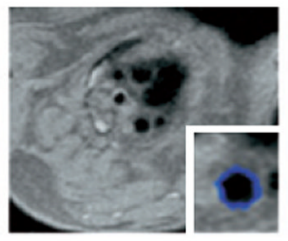

Week 4

enhancement
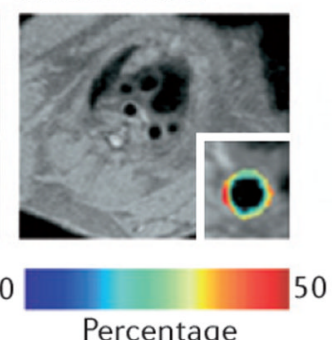

b
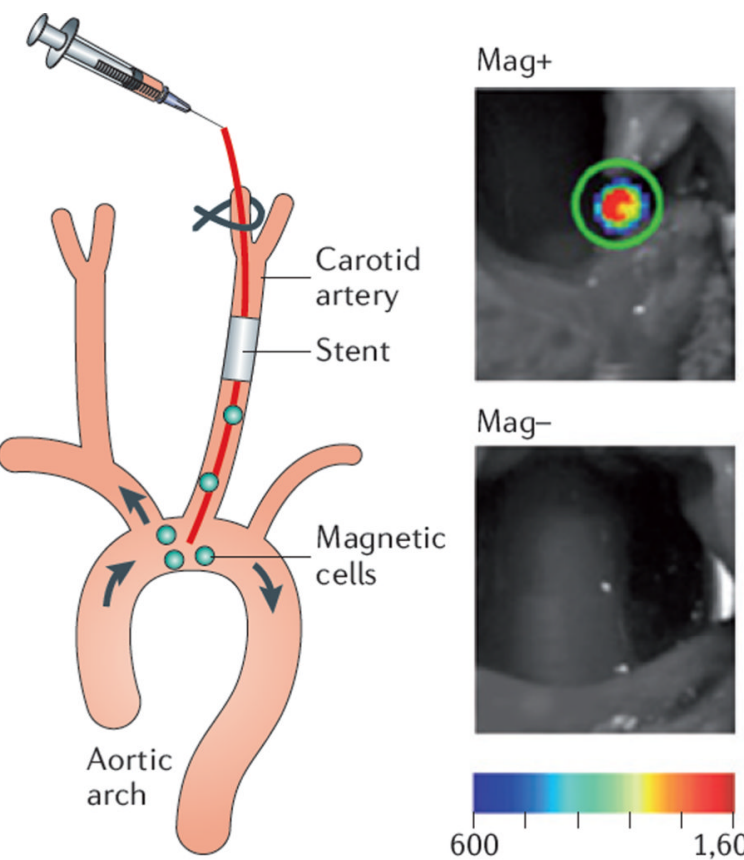

Mag-

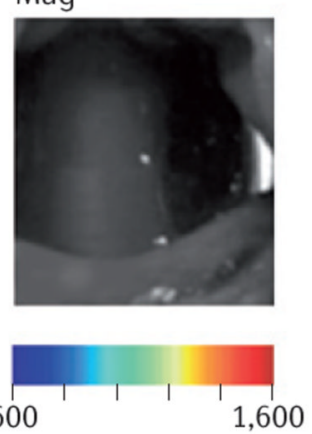

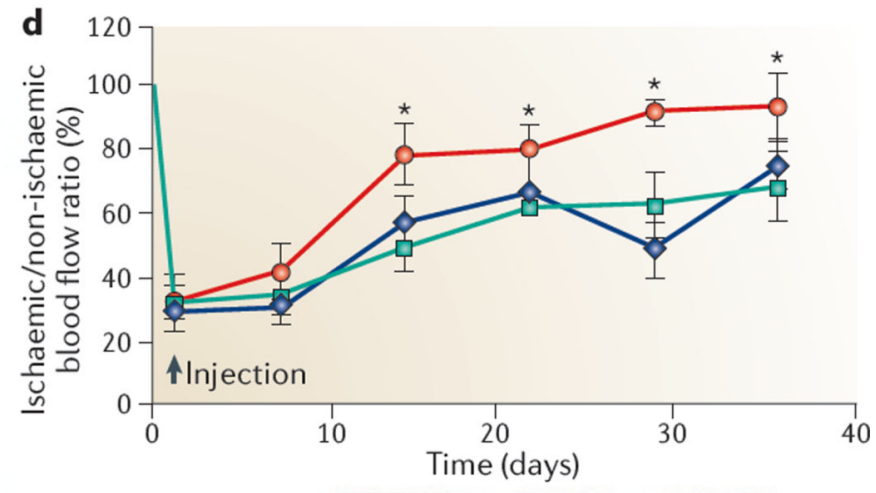

\section{- Au-NP-VEGF \\ $\sim$ VEGF \\ -ㅁ-Blank}

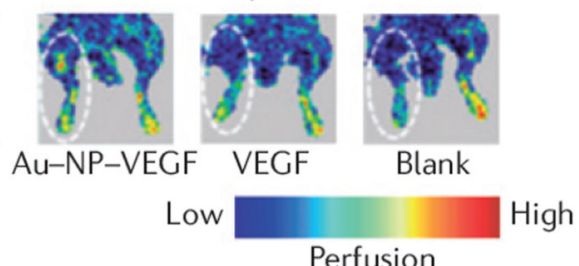

Figure 3. Imaging-assisted evaluation of nanomedical treatments in atherosclerosis

a The graph shows the therapeutic efficacy of a single intravenous injection of liposomeencapsulated prednisolone phosphate (L-PLP) compared to intravenous injection of prednisolone phosphate (PLP), measured by the standard uptake value (SUV), using ${ }^{18} \mathrm{~F}$ fludeoxyglucose in combination with positron emission tomography and computed tomography. SUV is the corrected tissue concentration divided by the injected dose per body weight. Statistically significant improvements in therapeutic effect can be seen after 2 days, lasting up to 7 days. Below the graph, magnetic resonance imaging (MRI) scans of gadolinium-labelled PLP show signal enhancement in a rabbit atherosclerotic abdominal aorta (depicted on the image with a white arrow) following the injection of liposomes (the image on the right and inset) compared to the baseline scan (the image on the left and inset). 
b | The figure shows an experimental setup of rats with stainless steel stents in their carotid arteries; these rats were intra-arterially injected with superparamagnetic fluorescent nanoparticles that were preloaded into endothelial cells for the purpose of reendothelialization. The rats were subsequently exposed to a homogenous magnetic field and showed high uptake of cells within the stent, which was detected with intravital bioluminescence imaging. The image at the top represents treatment in the presence of a magnetic field $\left(\mathrm{Mag}^{+}\right)$, whereas the image at the bottom represents treatment without a magnetic field $\left(\mathrm{Mag}^{-}\right) . \mathbf{c} \mid$ The images represent molecular imaging of angiogenesis by MRI, with segmentation of the aortic wall and colour-coded signal enhancement before and after the administration of anti-angiogenic perfluorocarbon nanoparticles targeting a V $\beta 3$ integrin. The colour-coded overlay indicating the percentage of signal enhancement shows a decrease in the signal after 1 week, which gradually increases after 2 and 3 weeks of treatment; after 4 weeks the level of signal enhancement is almost identical to the image taken at week $0 . \mathbf{d}$ | Therapeutic angiogenesis in a murine ischaemic hindlimb model is shown, using the delivery of exogenous vascular endothelial growth factor (VEGF) conjugated to nanoparticles. The graph represents a quantitative analysis of tissue blood perfusion in the murine model over 5 weeks. A statistically significant higher blood flow perfusion was observed following the injection of VEGF-conjugated gold nanoparticles (Au-NP-VEGF) as compared to free VEGF or no treatment (blank). The insets show representative images of laser Doppler perfusion imaging. Panel a is modified, with permission, from REF. 82 () (2010) American Chemical Society. Panel b is modified, with permission, from REF. 102 () (2008) National Academy of Sciences, USA. Panel $\mathbf{c}$ is modified, with permission, from REF. 108 @ (2008) American College of Cardiology. Panel d is modified, with permission, from REF. 111 () (2011) American Chemical Society. 


\section{A Nanoparticle biodistribution}

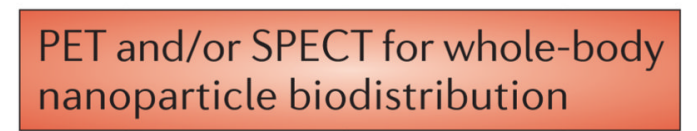

\section{B Imaging as a biomarker and therapeutic end point}
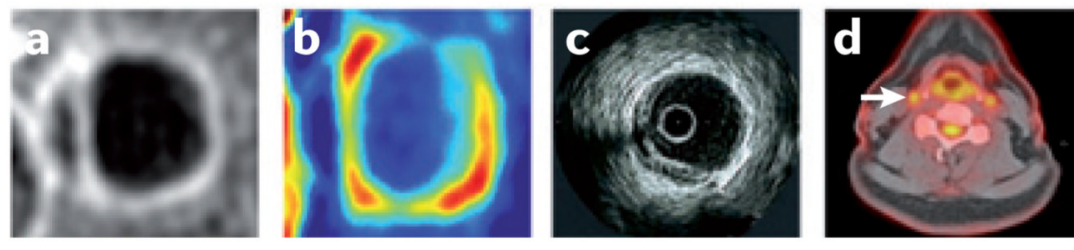

\section{arteries C Nanoparticle-facilitated molecular imaging}

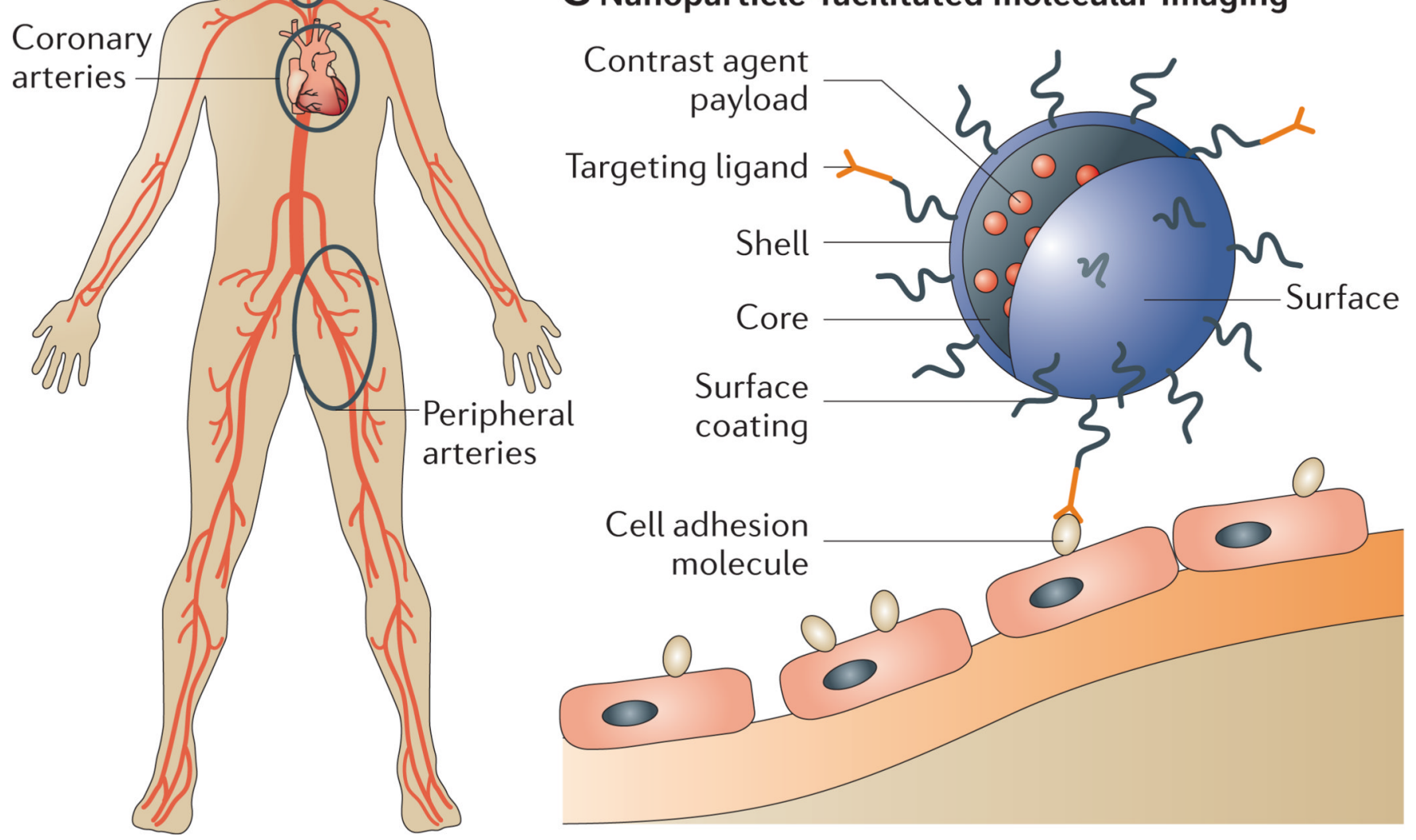

Figure 4. Imaging and nanomedicine in atherosclerosis

This figure provides examples of the ways in which imaging is associated with nanomedicine. A | The figure depicts the systemic arterial vasculature, highlighting the carotid arteries, coronary arteries and peripheral arteries, which are prone to developing vulnerable lesions that can be visualized by imaging. B | State-of-the-art imaging techniques that are used to visualize plaque morphology and plaque processes are shown. Ba $\mid$ The image shows a T1-weighted contrast-enhanced magnetic resonance imaging (MRI) scan of a carotid artery, showing thickening of the arterial wall. MRI can provide information on anatomical features and can be used to differentiate between the fibrous cap and lipid core. $\mathbf{B b} \mid$ The image depicts the same carotid vessel illustrated in part Ba, which has been assessed using dynamic contrast-enhanced MRI; this imaging technique provides information on vascular permeability and neovascularization. Bc | An intravascular ultrasound image is shown in the figure; intravascular ultrasound imaging can be used to obtain information on plaque area within coronary arteries in response to treatment. Bd |A fused image, obtained using ${ }^{18} \mathrm{~F}$-fludeoxyglucose imaging in combination with positron emission tomography (PET) and computed tomography imaging, is shown. The white arrow 
in the image points to the right carotid artery, showing a high amount of signal, which is indicative of metabolic activity within an atherosclerotic plaque. $\mathbf{C} \mid$ The figure shows a nanoparticle attaching to an endothelial cell lining the atherosclerotic plaque. The contrast payload within the nanoparticle can render it detectable by an imaging modality of choice. SPECT, single-photon emission computed tomography. Image Bc is modified, with permission, from REF. 63 ( ) (2006) American College of Cardiology. 


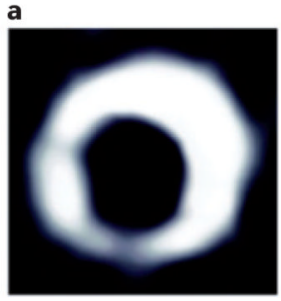

b
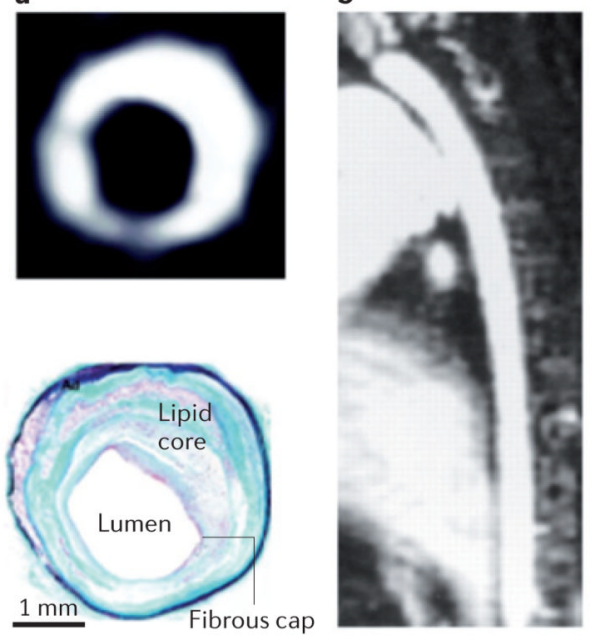

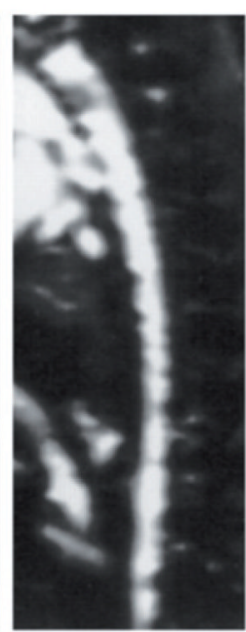

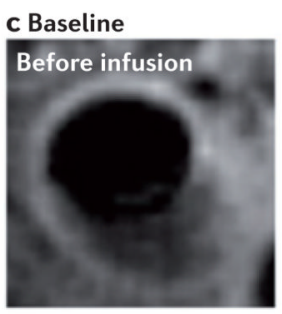
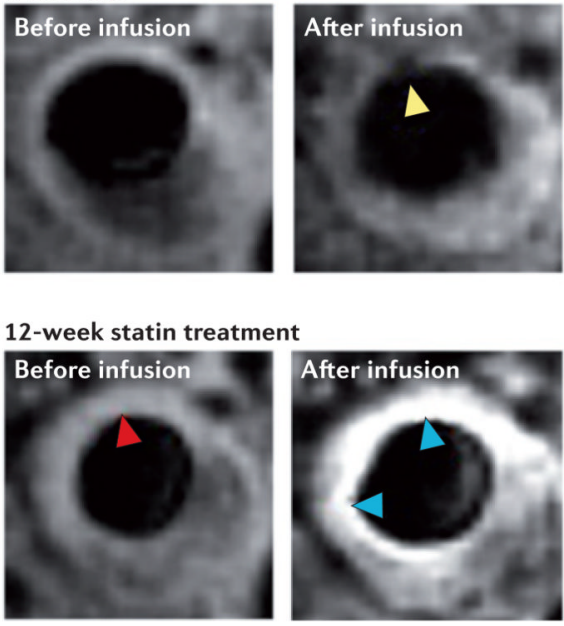

d

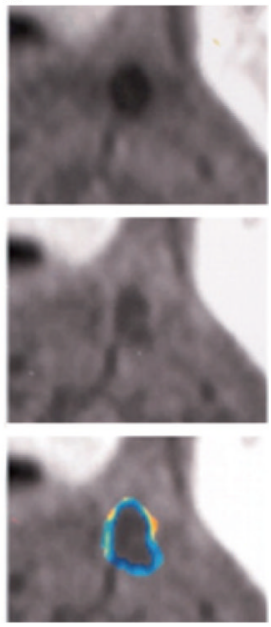

e
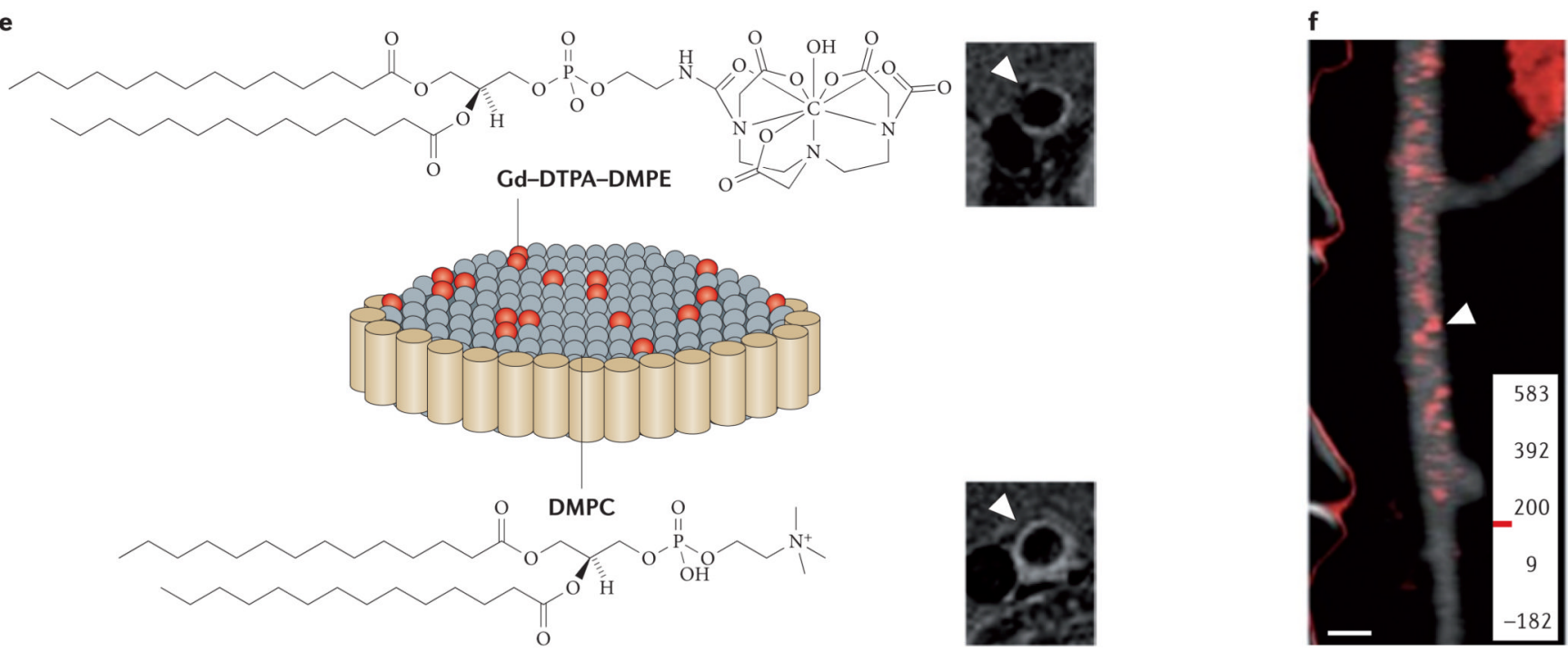

Figure 5. Nanoparticle-enhanced (molecular) imaging of atherosclerosis

a The image at the top of the panel, obtained by magnetic resonance imaging (MRI), shows the abdominal aorta of an atherosclerotic rabbit 24 hours after gadofluorine injection; as illustrated by the image, plaque enhancement is observed after injection. The appearance of the image closely correlates with the corresponding histopathological section (shown at the bottom of the panel). b An MRI scan of a hyperlipidaemic rabbit aorta is shown on the left of the panel. The image on the right is taken from the same rabbit model 5 days after the intravenous injection of ultrasmall superparamagnetic particles of iron oxide (USPIOs). Signal voids can be seen within the vessel wall, representing the uptake of iron oxide in plaque-embedded macrophages. $\mathbf{c}$ |MRI scans of the left common carotid artery are shown, before and after USPIO infusion at baseline and after 12 weeks of statin treatment. PreUSPIO imaging remains very similar in both time points, indicating that USPIOs from the baseline imaging session were not present in the plaque at 12 weeks. Signal enhancement (indicated by the blue arrowheads on the image) can be seen after 12 weeks of treatment, with no evidence of signal voids. The yellow arrowheads indicate signal void due to USPIO accumulation. The red arrowheads indicate that USPIO was not retained in the plaque, as the signal void at 12 weeks is not appreciable anymore. d | Molecular imaging of atherosclerotic plaque angiogenesis with perfluorocarbon nanoparticles targeting a V $\beta 3$ integrin is shown. 
MRI scans of the hyperlipidaemic rabbit aorta pre-injection of perfluorocarbon nanoparticles (at the top of the panel) and post-injection (in the middle of the panel) are shown, along with colour-coded signal enhancement (at the bottom of the panel). e | The figure shown is a schematic depiction of a discoidal high-density lipoprotein agent with gadolinium-lipid incorporated in the phospholipid coating. Representative MRI scans of the aorta of apolipoprotein E knockout mice are shown pre-injection of a high-density lipoprotein agent (at the top of the panel) and 24 hours post-injection (at the bottom of the panel). $\mathbf{f} \mid$ The image shows a computed tomography scan of regions in which high densities (shown in red) of the contrast agent $\mathrm{N} 1177$ have accumulated in an atherosclerotic rabbit aorta 2 hours after injection of N1177. DMPC, dimyristoylphosphatidylcholine; DMPE,

dimyristoylphosphatidylethanolamine; DTPA, diethylenetriamine pentaacetic acid; Gd, gadolinium. Panel a is modified, with permission, from REF. 125 ( ) (2004) American Heart Association. Panel b is modified, with permission, from REF. 126 ( ) (2001) American Heart Association. Panel $\mathbf{c}$ is modified, with permission, from REF. 129 () (2009) American College of Cardiology. Panel d is modified, with permission, from REF. 133 () (2003) American Heart Association. Panel e is modified, with permission, from REF. 136 () (2009) American Chemical Society. Panel $\mathbf{f}$ is modified, with permission, from REF. 141 () (2007) Macmillan Publishers Ltd. All rights reserved. 

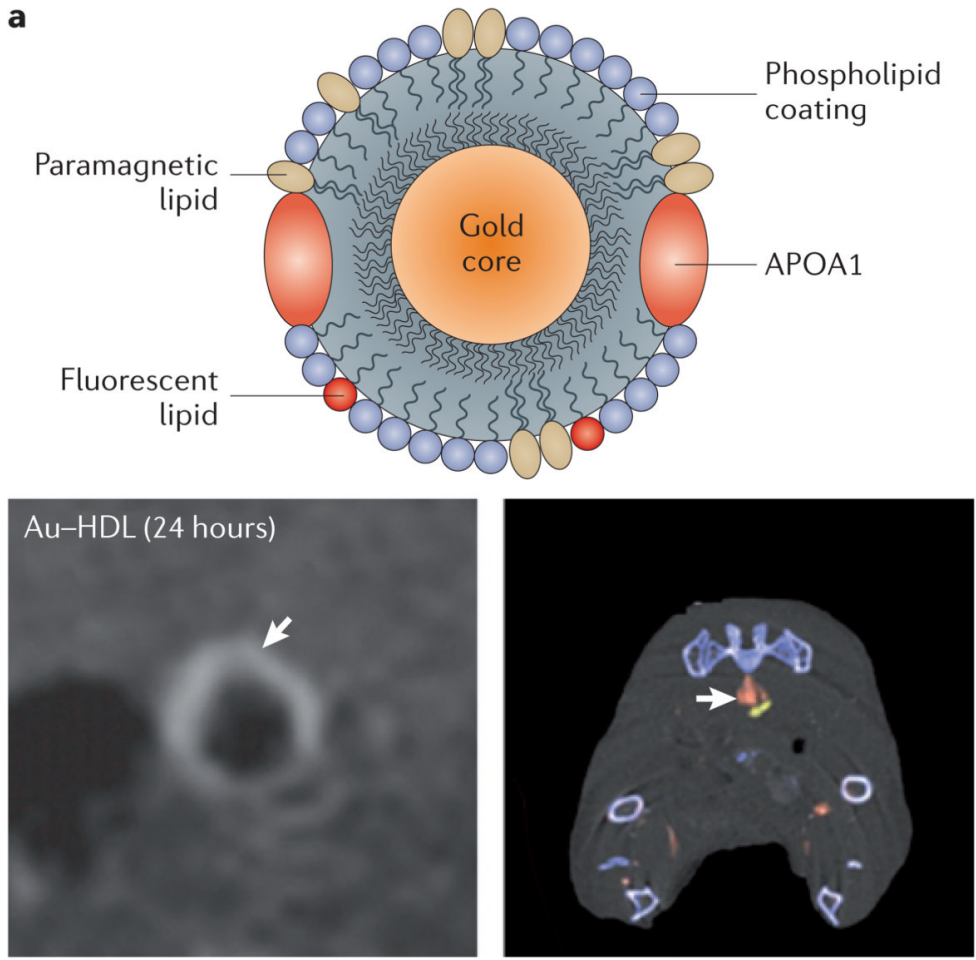

Dual fluorochrome-labelled

peptide (quenched fluorescence)
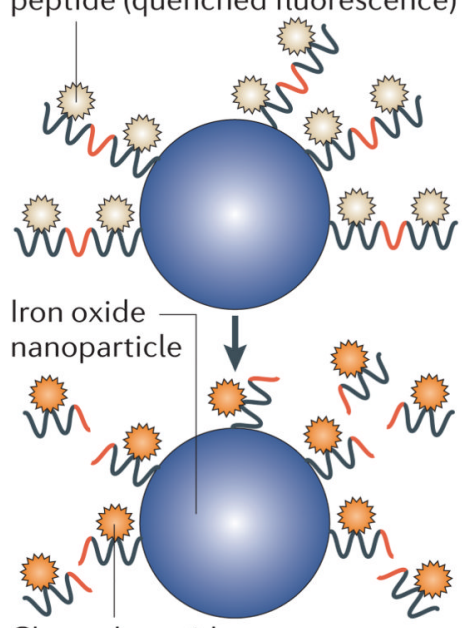

Cleaved peptide

(unquenched fluorescence)
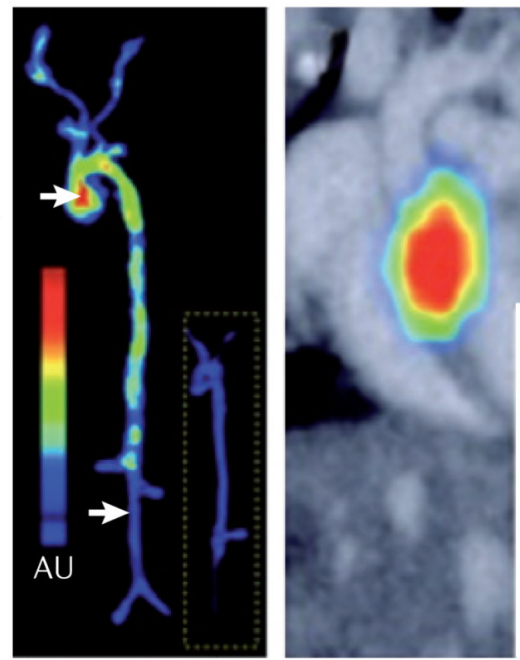

b
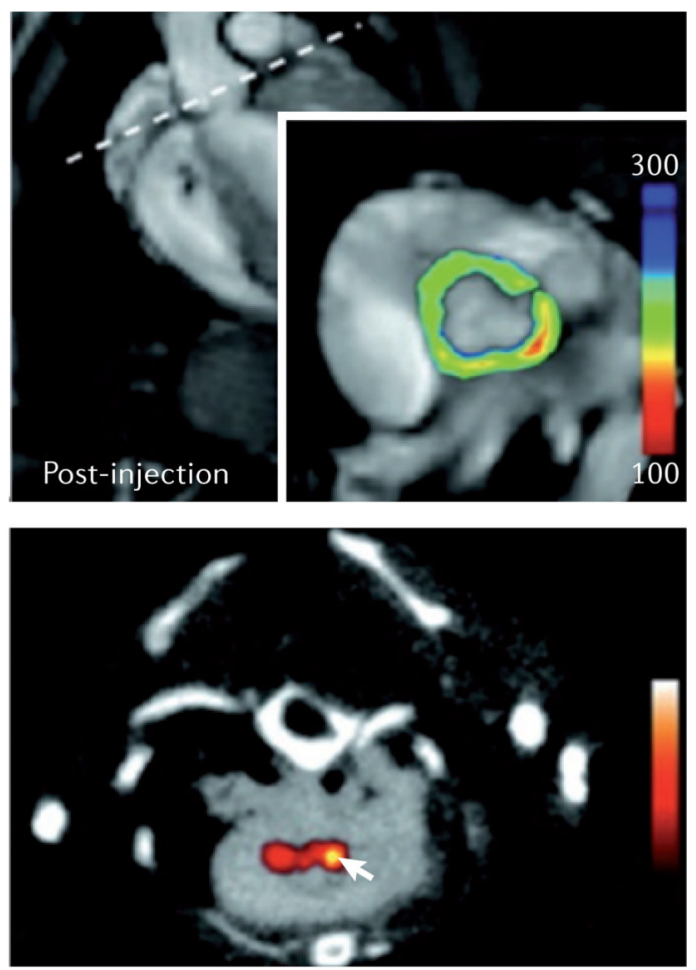
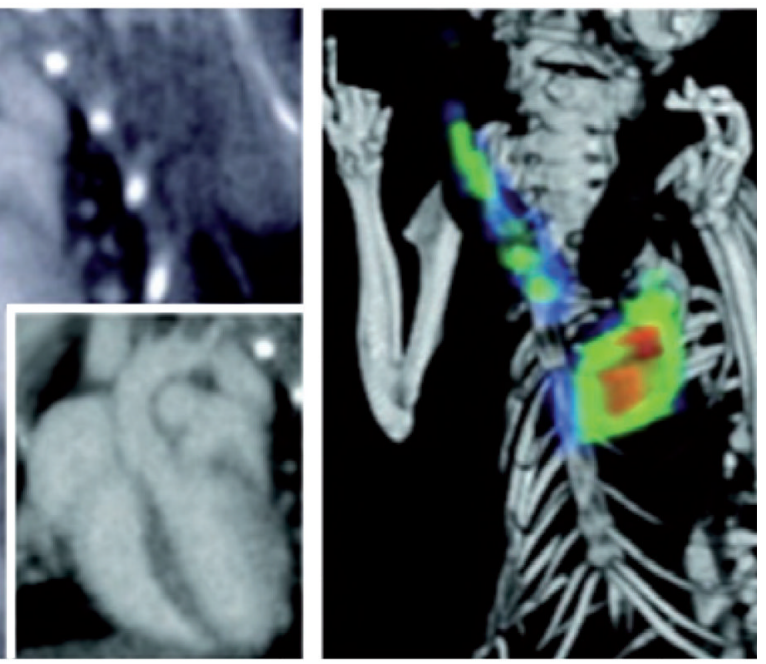

Figure 6. Nanoparticle-enhanced multimodal imaging of atherosclerosis

a A schematic illustration of a gold-core high-density lipoprotein (Au-HDL) nanoparticle is shown, with different components highlighted. The gold core can be replaced by iron oxides or quantum dots to enable magnetic resonance imaging (MRI) and optical imaging. The MRI scan (shown in the bottom left of the panel) shows signal enhancement in the abdominal aorta of an apolipoprotein E (APOE)-knockout mouse 24 hours after injection of the Au-HDL nanoparticle. A spectral computed tomography (CT) image is shown (in the bottom right of the panel) of the aorta of an APOE-knockout mouse injected with the $\mathrm{Au}-$ HDL nanoparticle and an iodinated emulsion contrast agent. The gold colour in the scan represents $\mathrm{Au}-\mathrm{HDL}$ accumulation in the macrophage-rich atherosclerotic plaque, and the 
red colour represents the iodinated emulsion. The components can clearly be differentiated. b | The image at the top of the panel, obtained using positron emission tomography (PET)CT shows signal enhancement in the posterior aortic root of an APOE-knockout mouse after the injection of a magnetofluorescent nanoparticle labelled with the radiolabelled PET tracer ${ }^{64} \mathrm{Cu}$. The MRI scan at the bottom of the panel shows substantial contrast enhancement in the aortic root 48 hours after injection of the nanoparticle. $\mathbf{c} \mid$ A scheme of probe design is illustrated. The first panel shows a fluorochrome-labelled peptide that is conjugated to a polymeric nanoparticle with an iron oxide core. When it is uncleaved the fluorochrome is quenched and does not emit a signal. In the presence of active proteases the fluorochrome is cleaved and liberated from the nanoparticle - it is consequently unquenched and thereby emits fluorescence. The second panel shows excised aortas from an APOE-knockout mouse and a wild-type mouse (inset) 24 hours after the injection of a protease sensor; the images are obtained via fluorescence reflectance imaging. The signal intensity is substantially higher in vascular areas with the plaque than in areas without the plaque. The skeletal and vascular anatomy of an APOE-knockout mouse injected with respective protease sensors is shown in the third panel (via in vivo fluorescence molecular tomography (FMT)-CT imaging with two-dimensional FMT-CT (long-axis view)) and in the fourth panel (via three-dimensional maximum-intensity projection).The fluorescence signal is observed in the aortic root and arch, and additional activation of the sensor is observed in the carotid artery. Panel $\mathbf{a}$ is modified, with permission, from REF. 137 ( (2008) American Chemical Society, and from REF. 142 @ (2010) Radiological Society of North America. Panel b is modified, with permission, from REF. 148 ( $(2008)$ American Heart Association. Panel $\mathbf{c}$ is modified with permission from REF. 151 () (2009) American Heart Association. 


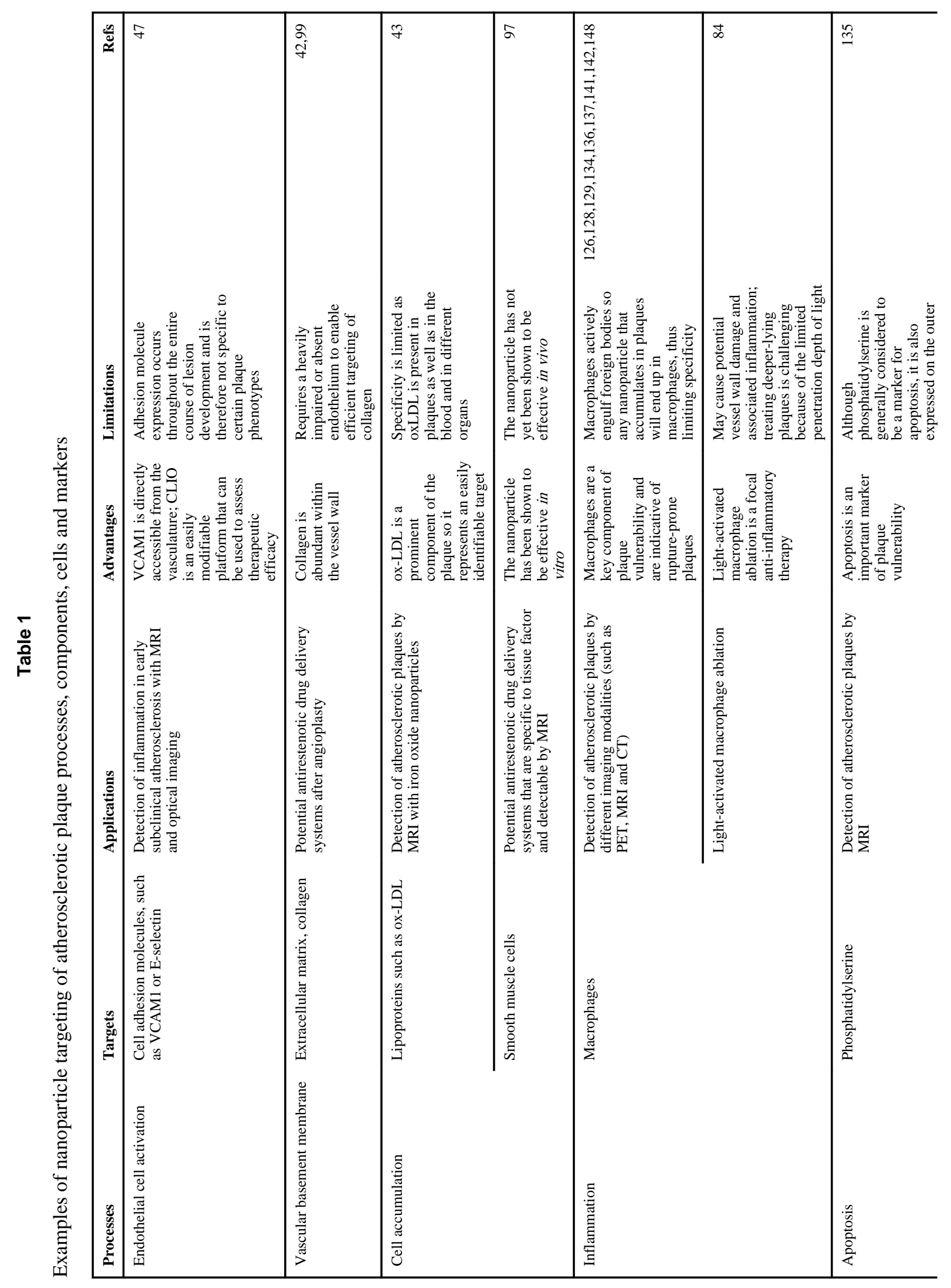

Nat Rev Drug Discov. Author manuscript; available in PMC 2013 April 11. 


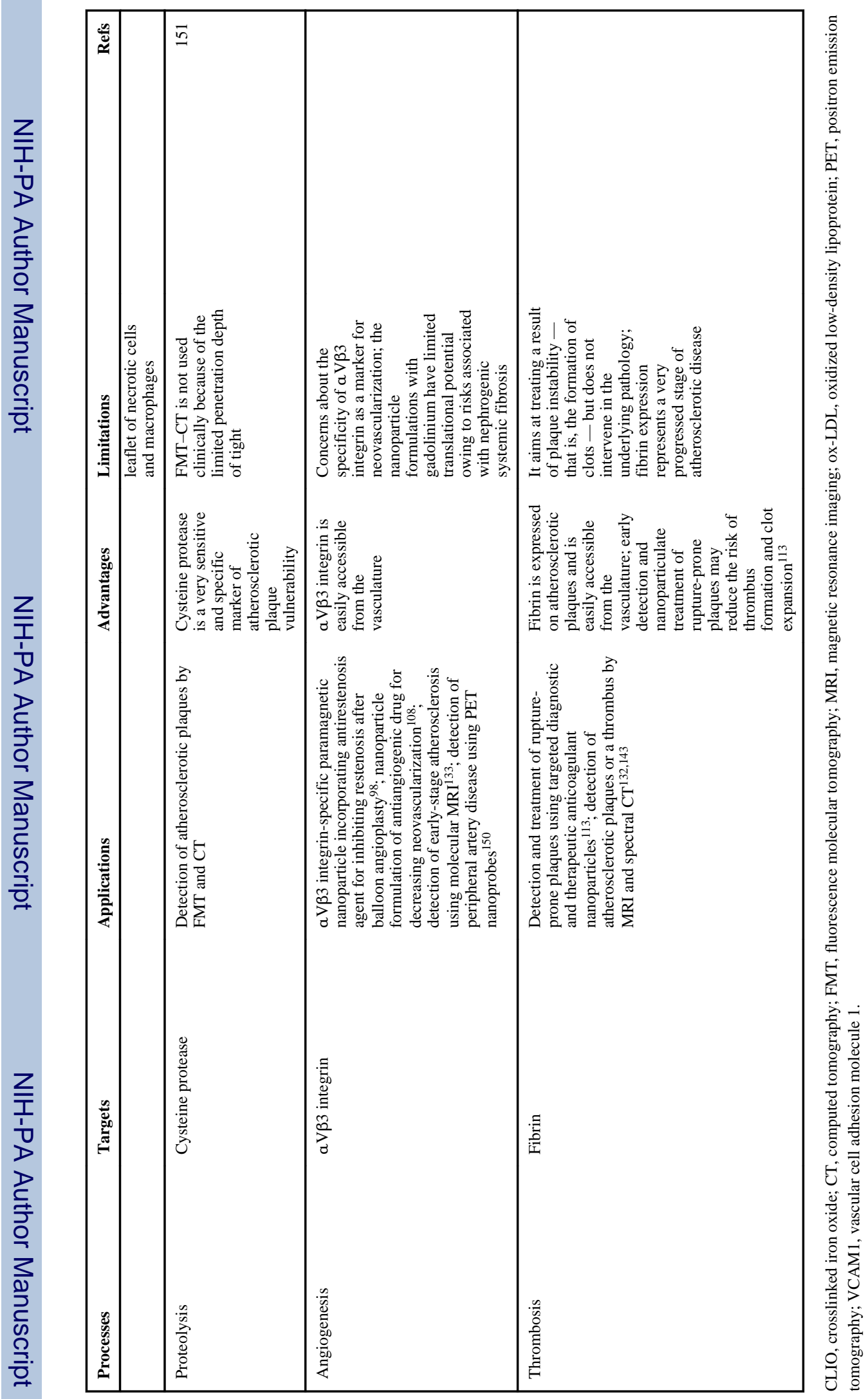

